University of Louisville ThinkIR: The University of Louisville's Institutional Repository

Electronic Theses and Dissertations

$8-2019$

\title{
Probability of conception after fertility counseling and the association of sexually transmitted infections with pregnancy in the Loussi study.
}

Lindsey Adelle Wood

University of Louisville

Follow this and additional works at: https://ir.library.louisville.edu/etd

Part of the Epidemiology Commons

\section{Recommended Citation}

Wood, Lindsey Adelle, "Probability of conception after fertility counseling and the association of sexually transmitted infections with pregnancy in the Loussi study." (2019). Electronic Theses and Dissertations. Paper 3262.

https://doi.org/10.18297/etd/3262

This Master's Thesis is brought to you for free and open access by ThinkIR: The University of Louisville's Institutional Repository. It has been accepted for inclusion in Electronic Theses and Dissertations by an authorized administrator of ThinkIR: The University of Louisville's Institutional Repository. This title appears here courtesy of the author, who has retained all other copyrights. For more information, please contact thinkir@louisville.edu. 


\title{
PROBABILITY OF CONCEPTION AFTER FERTILITY COUNSELING AND THE ASSOCIATION OF SEXUALLY TRANSMITTED INFECTIONS WITH PREGNANCY IN THE LOUSSI STUDY
}

\author{
By \\ Lindsey Adelle Wood \\ B.S., Southern Arkansas University, 2017

\begin{abstract}
A Thesis
Submitted to the Faculty of the in Partial Fulfillment of the Requirements for the Degree of

Master of Science

in Epidemiology

Department of Epidemiology and Population Health

University of Louisville

Louisville, Kentucky
\end{abstract} \\ School of Public Health and Information Sciences of the University of Louisville
}

August 2019 

PROBABILITY OF CONCEPTION AFTER FERTILITY COUNSELING AND THE ASSOCIATION OF SEXUALLY TRANSMITTED INFECTIONS WITH PREGNANCY IN THE LOUSSI STUDY

\author{
By \\ Lindsey Adelle Wood \\ B.S., Southern Arkansas University, 2017 \\ A Thesis Approved on
}

July 24, 2019

By the following Thesis Committee:

\begin{tabular}{c}
\hline Dr. Kira Taylor \\
\hline Dr. Anne Wallis \\
\hline Dr. Jeremy Gaskins
\end{tabular}




\section{DEDICATION}

This thesis is dedicated to my mother and my grandmother,

Ms. Sandra Kaye Wood

and

Ms. Glenda Jean Conyers "Mama Jean"

I am because of you. 


\section{ACKNOWLEDGEMENTS}

I would like to thank my mentor and chair, Dr. Kira Taylor, for correcting my works when they were bad, and praising my works when they were good. I have grown from "bright-eyed and bushy-tailed" to the epidemiologist I am today due to your patience, time, and effort; thank for choosing me and for investing in me. I would also like to thank my committee members, Dr. Anne Wallis and Dr. Jeremy Gaskins, for their comments; this thesis would be nothing without your words of encouragement and guidance. I would also like to recognize the faculty and my colleagues in the Department of Epidemiology who have always encouraged me and reminded me that I am exactly where I need to be. Special thanks to T'Shura Ali for being a great team member on the LOUSSI Study.

To my family - Mom, Dad, Mama Jean, Bubba - I do everything in life to make each of you proud. You see my worth when I can't see it in myself. Thank you for the life you've given me, your unending support, and your love.

Dr. Joy Hart and Dr. Kandi Walker, firstly, thank you for funding my education. More importantly, thank you for being my friends and the best support system I could ask for. My life in Louisville would not be the same without you two.

Finally, to my fiercely supportive friends, Jade Halliburton, Norma Aranda Smith, and Shelby Carter. Thank you for lifting me up when I needed it and for 
always being prouder of me than I am of myself. I define friendship with each of your names. 


\begin{abstract}
PROBABILITY OF CONCEPTION AFTER FERTILITY COUNSELING AND THE ASSOCIATION OF SEXUALLY TRANSMITTED INFECTIONS WITH PREGNANCY IN THE LOUSSI STUDY

Lindsey Adelle Wood
\end{abstract}

July 24,2019

This study interrogated predictors of pregnancy and the effect of a history of sexually transmitted infection (STI) on probability of conception among a cohort of women seeking fertility counseling $(\mathrm{N}=170)$, using multivariable logistic regression and Cox proportional hazards models. There were 76 (44.7\%) total pregnancies. $32(39.0 \%)$ were achieved spontaneously by women who never received ART (N=82). Among women who did receive ART (N=88), 35 (39.7\%) were achieved by ART and 9 (10.2\%) achieved spontaneously. Among the full cohort $(\mathrm{N}=170)$, obesity was a significant negative predictor of pregnancy while history of human papilloma virus was a significant negative predictor of time to pregnancy. Among those who did receive ART ( $N=88)$, ovarian infertility diagnosis was a significant positive predictor of pregnancy, relative to other infertility diagnoses. History of STI was nonsignificantly associated with increased probability of pregnancy in all sub-samples, though this result may be confounded by characteristics like coital frequency. 


\section{TABLE OF CONTENTS}

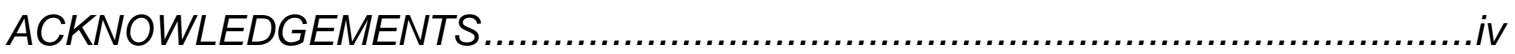

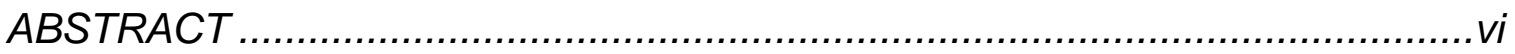

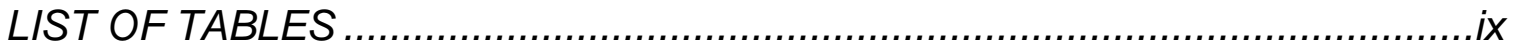

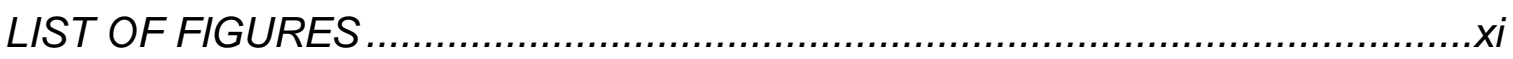

A. INTRODUCTION..................................................................................... 1

B. SPECIFIC AIMS AND HYPOTHESES ….................................................. 4

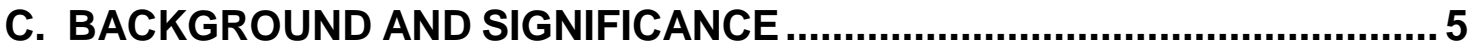

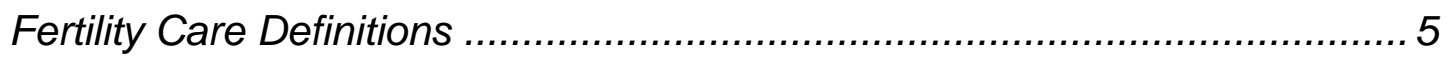

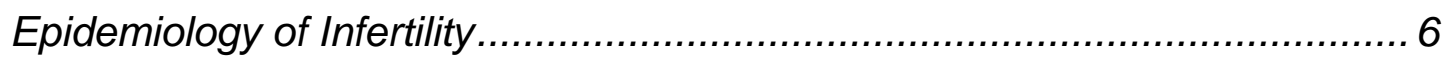

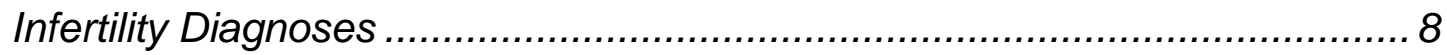

Treatments for Infertility ................................................................... 16

Infertility and Spontaneous Conception ................................................ 21

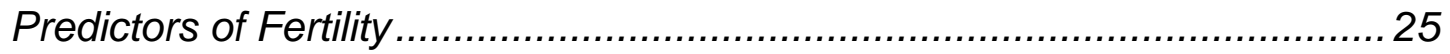

D. METHODS

LOUSSI Study Recruitment and Baseline Data Collection ......................... 47

Follow-Up Data Collection ...................................................................... 48

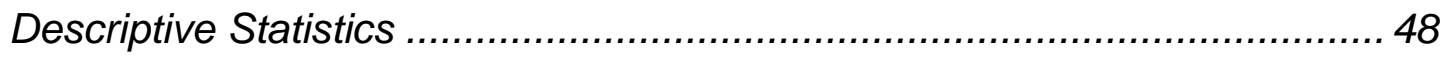

Etiologic Logistic Regression Modeling ............................................... 49

Predictive Logistic Regression Modeling ............................................... 52

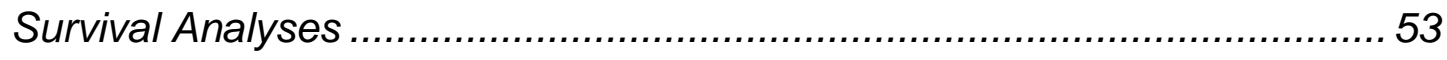

E. RESULTS

Descriptive Statistics by Conception Status Among all Sub-Samples .......... 57

Descriptive Statistics by STI Status ......................................................... 67 


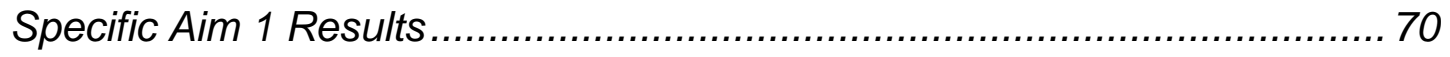

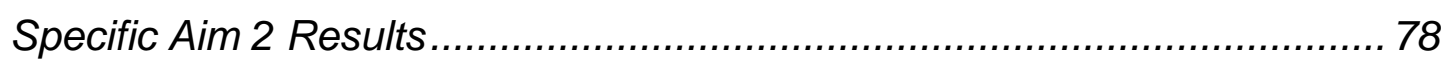

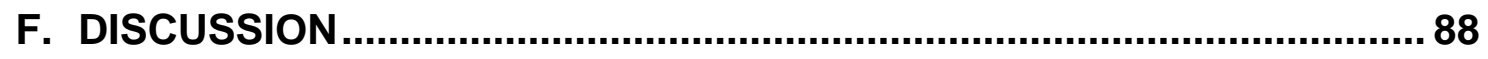

Spontaneous Conception Rates........................................................ 91

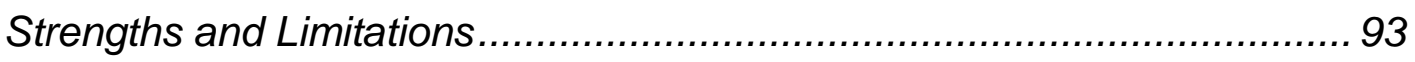

Suggestions for Further Research ..................................................... 95

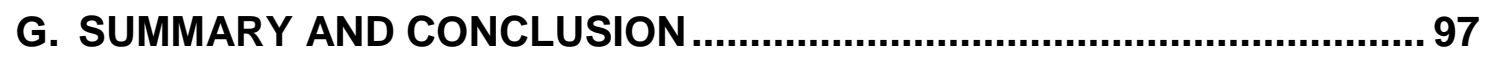

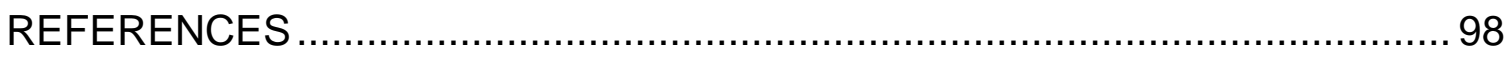

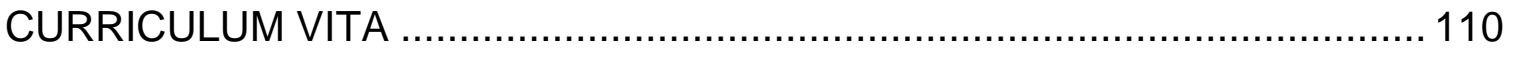




\section{LIST OF TABLES}

1. Spontaneous Conception and Live Birth Rates Among Infertile Couples 22

2. Variable Definitions and Treatment in Modeling 50

3. Characteristics Among Entire Follow-Up Stratified by Conception Status $(N=170)$

4. Characteristics Among Those with No ART Stratified by Conception Status $(N=82)$.

5. Characteristics Among Those with ART Stratified by Conception Status $(N=88)$

6. Characteristics Among Entire Follow-Up Stratified by History of STI $(N=170)$

7. Final Logistic Regression Models for the Effect of History of STI on the Probability of Pregnancy Among Each Sub-Sample. 72

8. Odds Ratios for the Effect of History of STI on Pregnancy Among All SubSamples 72

9. Hazard Ratios for the Effect of History of STI on Time to Pregnancy Among All Sub-Samples

10. Predictive Logistic Regression Model on Conception for The Entire Cohort $(N=170)$

11. Predictive Logistic Regression Model on Conception for Women with No $\operatorname{Art}(\mathrm{N}=82)$

12. Predictive Logistic Regression Model on Conception for Women with Art $(N=88)$ 
13. Final Predictive Logistic Regression Models for Probability of Pregnancy Among Each Sub-Sample................................................................... 82

14. Predictive Cox Model of Conception for The Entire Cohort ( $N=170)$

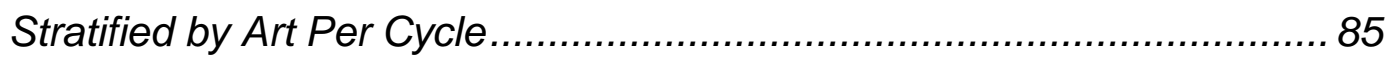

15. Predictive Cox Model of Conception for Women with No Art, (N=82) ...... 86 16. Predictive Cox Model for Women with Art $(N=88)$ Stratified by Art Per

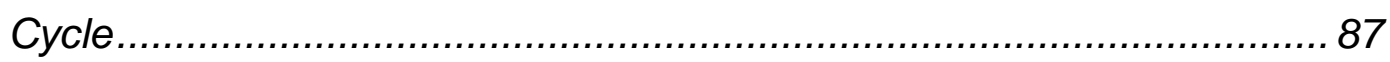




\section{LIST OF FIGURES}

1. Flow Diagram for Participants with Follow-Up Information. ....................56

2. Flow Diagram for the Three Sub-Samples of the Study ….....................57

3. Adjusted Survival Curves for History of STI Among the Entire Cohort,

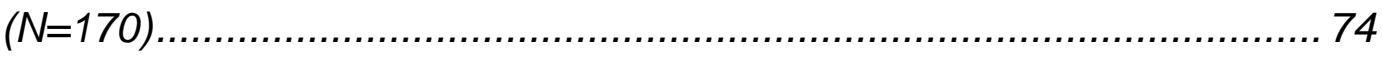

4. Ln(-In) Curves of Estimated Survivor Functions of History of STI Among

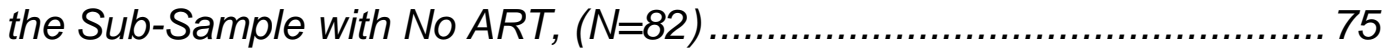

5. Ln(-In) Curves of Estimated Survivor Functions of Obesity Among the

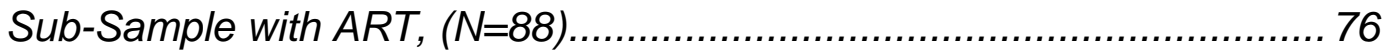

6. Adjusted Survival Curves for History of STI Among Those with ART,

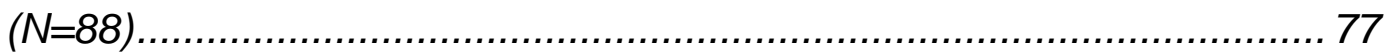




\section{A. INTRODUCTION}

The clinical definition of infertility is "the failure to achieve a clinical pregnancy after 12 months or more of regular unprotected sexual intercourse" [1]. When such a failure occurs, many couples find assisted reproductive therapy (ART) an attractive option. These therapies include, but are not limited to, in-vitro fertilization (IVF) and intracytoplasmic sperm injection (ICSI). Some treatments end successfully, with the patient having an assisted conception and live birth. However, some treatments are unsuccessful in that they do not produce a conception. In this case, the patient has the option to continue therapy with more cycles, or to discontinue treatment for varying reasons, such as the stresses that can be induced during treatment or the cost of the treatment.

After discontinuation of ART, either successful or otherwise, or even if no ART was ever received, there is still a possibility that an infertile patient may have a spontaneous conception, meaning that the patient conceived on their own while not receiving any form of ART. Varying studies have found spontaneous conception rates after ART treatment to be anywhere from $17 \%$ to $34 \%[2-8]$. These studies, however, vary in their defined population. For example, some studies [3-6] only include patients that had live births from IVF or ICSI, while others $[7,8]$ include successful and unsuccessful treatments from ART, while still others only include those who had unsuccessful treatment [2] or a specific infertility diagnosis [9]. 
Fertility in women can be affected by the woman's history of a handful of STIs [10-19]. Chlamydia, specifically, is the major cause of pelvic inflammatory disease (PID), which can lead to tubal factor infertility, and can also lead to adverse pregnancy outcomes such as ectopic pregnancy via PID, premature rupture of the membrane, preterm birth, low birth weight, and stillbirth [10]. Also, although it is well known that HPV is the cause of most, if not all, cervical cancers, chlamydia is thought to play a significant cofactor role in these developments [10]. Gonorrhea can also lead to PID, although higher proportions of chlamydia than gonorrhea have been found in women with PID [11]. Likewise, gonorrhea has been associated with endometriosis diagnosis, although not as associated as chlamydia [12]. Salpingitis (inflammation of the fallopian tubes) associated with chlamydia and gonorrhea is causal of tubal infertility [13, 14]. Gonorrhea infection is not as strongly associated with tubal infertility as chlamydia is $[15,16]$, and likelihood of conception for any type of infertility is higher in those with gonorrhea infection than with chlamydia infection [14]. The effects of HPV on infertility are well-established in males, but little is known about the effects on infertility in women $[17,18]$. It is established, however, that HPV infection in women can cause adverse pregnancy outcomes, such as miscarriage and the premature rupture of the membrane [18]. The effects of herpes simplex virus on male infertility is also well-established, but herpes infection has no association with cervical factor infertility [19]. Herpes may, however, be associated with PID, although this is not definitive [20]. For all of these reasons, it 
is somewhat surprising that few studies have included STI history while conducting conception analyses among infertile couples.

The purpose of this study is to determine the effects of STI history on the likelihood of achieving pregnancy and on the time to achieve pregnancy among a cohort of women seeking infertility treatment, whether or not they received ART treatments. Also, predictive models will be produced in order to determine which factors predict the likelihood of pregnancy and the time to achieve pregnancy among the infertile women. 


\section{B. SPECIFIC AIMS AND HYPOTHESES}

The primary objective of this study is to analyze numerous factors to determine their effects on the probability of achieving pregnancy and to assess which factors predict the time to achieve pregnancy among three sub-samples of the prospective LOUSSI cohort: 1) the entire prospective cohort of women seeking fertility care, 2) the women who have ever received ART treatments, and 3) the women who have never received ART treatments.

The specific aims of the study are as follows;

\section{Specific Aim 1: To estimate the effect of STI history on a) the} probability of pregnancy and b) the time to pregnancy. Hypothesis: a history of STI will be negatively associated with the probability of pregnancy and the time to pregnancy among all sub-samples.

Specific Aim 2: To identify factors which predict a) the probability of achieving pregnancy after fertility counseling and b) the time to achieving pregnancy. Hypothesis: factors that will predict the probability of pregnancy and the time to pregnancy will be age, obesity, AMH levels, unexplained infertility, and history of STI. 


\section{BACKGROUND AND SIGNIFICANCE}

\section{Fertility Care Definitions}

There are many terms that should be defined in order to obtain a full clinical understanding of fertility. In 2017, the World Health Organization (WHO) and the International Committee for Monitoring Assisted Reproductive Technologies (ICMART), along with other experts, revised the existing 2009 International Glossary on Infertility and Fertility Care [1]. As a result, The International Glossary on Infertility and Fertility Care, 2017 is an agreement on clinical definitions of infertility and other relevant terms [21].

Before being able to fully understand infertility, three important fertility care definitions need to be distinguished: "fertility," "fecundity," and "fecundability." "Fertility" is the ability to "establish a clinical pregnancy," where "clinical pregnancy" is a "pregnancy diagnosed by ultrasonographic visualization of one or more gestational sacs." Conversely, "fecundity" is the "capacity to have a live birth," where "live birth" is a birth in which the child is completely extracted from the mother after 22 weeks of gestation and shows evidence of live. Further, "fecundability" is the "probability of a pregnancy, during a single menstrual cycle in a woman with adequate exposure to sperm and no contraception, culminating in a live birth." In brief, "fertility" is the ability to achieve pregnancy, "fecundity" is 
the ability to achieve a live birth, and "fecundability" is the probability of achieving a pregnancy in one menstrual cycle leading to a live birth [21].

Often interchanged, "infertility" and "subfertility" are defined as "the failure to establish a clinical pregnancy after 12 months of regular, unprotected sexual intercourse." This means that any person who has not been preventing pregnancy, and has frequent coital activity, but has not achieved pregnancy within a year's time, is clinically infertile. However, the definition also states that "fertility interventions may be initiated in less than 1 year based on...age," meaning that providers can offer infertility treatments for women 35 years of age or older after only 6 months of trying and failing to achieve a pregnancy [22]. Additionally, an infertility diagnosis may not be definite; "sterility" is the term used when infertility becomes a permanent state. Infertility can either be a primary or secondary diagnosis for either a male or the female partner. One is diagnosed with "primary infertility" when he/she has never initiated or been diagnosed with a clinical pregnancy before. Conversely, "secondary infertility" is the state of infertility in a male whom has successfully initiated a clinical pregnancy or in a female who has been diagnosed as clinically pregnant.

\section{Epidemiology of Infertility}

The prevalence of infertility has proved to be difficult to estimate; the estimate can be easily affected by how the condition is being defined or diagnosed. One review paper concluded that based on the literature, it is nearly 
impossible to calculate a prevalence [23]. This is largely due to the inconsistency in calculating infertility, especially in calculating the denominators; some of which consist of women attempting conception, women who are currently married, being ever married, and even all women. However, a 2012 World Health Organization study used 277 national, regional, and global surveys on infertility to produce the best estimate of prevalence of infertility [24]. The authors greatly detailed the definitions of their calculations; in the numerator of primary infertility prevalence were women whom were part of an infertile couple, while the denominator was women who were a part of infertile couples and a part of fertile couples - of which had one successful live birth and have been in the same relationship for at least five years. Likewise, in the numerator of the prevalence of secondary infertility were women whom were part of an infertile couple, but the denominator included women whom were a part of an infertile couple and women whom were a part of a fertile couple - of which had one successful live birth within the past five years and were in the same relationship five years after their first live birth. The authors concluded that the prevalence of primary infertility in 2010 among women seeking to have a child was $2.7 \%, 2.0 \%$, and $1.6 \%$ in age ranges of 20-24 years, 25-29 years, and 30-44 years, respectively. The overall primary infertility and secondary infertility prevalence for 2010 was $1.9 \%$ and $10.5 \%$, respectively. In 2010 , women in the United States of America had a fairly low prevalence of secondary infertility of under $6 \%$, while some countries in Eastern Europe and Central Asia had a secondary infertility prevalence of over $16 \%$. It was also estimated that there are 19.2 million and 29.3 million couples 
with primary and secondary infertility, summing at 48.5 million couples with infertility, globally.

Within the United States, infertility among women has decreased from 1965 to 2010 [25]. A CDC study reported that $11.2 \%, 8.5 \%$ and $6.0 \%$ of married women ages 15-44 in the United States were infertile in 1965, 1982, and 20062010 , respectively. The number of women infertile in 1965, 1982, and 2006-2010 were 2.96 million, 2.39 million, and 1.53 million, respectively. Between 2006 and 2010, estimates of primary infertility among married women ages $15-24,25-29$, $30-34,35-39$, and $40-44$ were $7 \%, 9 \%, 9 \%, 25 \%$, and $30 \%$, respectively, accounting for 700,000 infertile married women. Additionally, 830,000 married women between the ages of 15 and 44 experience secondary infertility between 2006 and 2010.

\section{Infertility Diagnoses}

There are many pathophysiology defects by which infertility can arise. In the female, defects can occur along any part of the reproductive system, including the fallopian tubes, the uterus or the endometrium, and the ovaries. In the male, defects of the sperm can arise through a number of causes. The cause of infertility in a couple could also be due to unknown causes, by which the cause of infertility is deemed as unexplained. This section dives into each infertility diagnosis, and the pathophysiology of each. 
Female: Tubal Factor

In the conception process, the role of the fallopian tubes is to transport the egg and the sperm, as well as to house a newly fertilized embryo during its first stages of development [26]. When the fallopian tubes are damaged, female infertility can occur. Tubal factor infertility refers to the blockage or occlusion of the fallopian tubes. When this occurs, infertility is potentially caused by 1) sperm being unable to fertilize the egg, or by 2) a fertilized egg not being able to reach the uterus to be implanted. Reported prevalence of tubal factor infertility among infertile couples in 2003 and 2008 ranges from $12 \%$ to $33 \%$ [26] and 25\% to 35\% [27], respectively.

There are several etiologies of tubal factor infertility, but the most common source is pelvic inflammatory disease (PID). It has been estimated that in the United States, $8 \%$ of women between the ages of 16 and 46 are diagnosed with PID, and more than 1 million women are treated for PID annually [28]. PID is strongly associated with tubal factor infertility, and as PID episodes increase, so does the rate of tubal factor infertility; after one, two, and three episodes, tubal infertility rates can be up $8 \%, 19.5 \%$, and $40 \%$, respectively [29]. It should be noted that PID is mainly caused by chlamydia infection and gonorrhea infection; however, for the purposes of this thesis, these topics are reviewed in a separate section.

Other, less common causes of tubal factor infertility are endometriosis, and surgical complications. Although endometriosis can be considered a female infertility diagnosis on its own, it can also contribute to development of tubal 
factor infertility; when pelvic adhesions are present from endometriosis near the fallopian tubes, it is possible that distortion occurs in the tubes [26]. Finally, prior abdominal surgeries can cause tubal factor infertility by promoting adhesions when the epithelial cells of the peritoneum do not regrow correctly [30].

Female: Uterine Factor

Regarding reproduction, the uterus plays an imperative role. The uterus is where a fertilized egg is implanted, and the uterus remains the home of the growing fetus until birth. There are several uterine factors that can inflict infertility on a woman, these include congenital factors, fibroids, intrauterine adhesions, endometriosis, and other cervical factors.

There are several congenital uterine disorders. These disorders are the most common genital tract abnormalities in females [28]. The most common congenital malformation of the uterus, and the most debated, is septate uterus i.e. uterine septum, a condition characterized by the upper wall of the uterus protruding into the wall of uterus, thereby creating a divide or septate [31]. Although septate uteri have been reported to be associated with recurrent pregnancy loss [28, 32], there is insufficient evidence to support the association between uterine septum and infertility [32, 33].

Uterine leiomyomata, i.e. myomas or fibroids, are benign tumors. Fibroids occur in $20 \%-40 \%$ of reproductive-aged women, making them the most common benign tumors among women of reproductive age [34]. One possible 
symptom of uterine fibroids is infertility; however, uterine fibroids are typically asymptomatic and infertility is a rare symptom [34]. When infertility does occur from fibroids, there are several mechanism of occurrence, including but not limited to obstruction of the fallopian tubes, distorted or inflamed endometrium, and reduced exposure to sperm as a result of a displaced cervix [35].

Intrauterine adhesions are also known to affect fertility in women, with estimates of $1.5 \%$ of infertile women experiencing them [36]. The most common symptoms of intrauterine adhesions are menstrual disruptions and infertility [37]. Infertility by intrauterine adhesions is caused through the uterine cavity becoming partially or completely obliterated from repeated curettage, mainly after abortions and delayed removal of the placenta after delivery [36]. Endometriosis is defined by the endometrial tissue being present outside of the endometrium, such as in the pelvic peritoneum or the ovaries [38]. Endometriosis affects $6-10 \%$ of all females [38] and 5-15\% of reproductive-aged women [28], but reaches to 35 $50 \%$ in women with pain or infertility [38]. Symptoms of endometriosis include chronic pelvic pain, abnormal uterine bleeding, and infertility [28]. Infertility caused by endometriosis is mainly due to the resulting inflammation, which can lead to dysfunction in ovulation, sperm phagocytosis, impaired fertilization, and problems with implantation [39]. Although the origins of endometriosis are widely unknown, the most accepted theory on the pathogenesis of endometriosis is Sampson's theory of retrograde menstruation: during menstruation, endometrial tissue flows up the fallopian tubes and into the peritoneal cavity [40]. Sampson's theory is also supported by his observation of menstrual blood leaving through 
the fallopian tubes and his findings of endometrial tissue in the lumen of some of his female patients with endometriosis [40]. However, Sampson' theory has faced questioning due to the fact that most women have retrograde menstruation, but only $6-10 \%$ of women are diagnosed with endometriosis [38]. There are now a number of theoretical pathogeneses of endometriosis, including genetic factors, immune factors, and some environmental factors.

The cervix is mainly responsible for keeping a fetus in the uterus until birth [41]. The mucus produced by the cervix changes during the menstrual cycle, and the production of abnormal mucus has been thought to inhibit the ability of sperm to enter the uterus [42]. However, cervical factors are rarely diagnosed as the main cause of infertility $[43,44]$. This is largely due to the fact that the diagnostic test for cervical factors, the post-coital test, is unreliable and does not predict infertility $[43,44]$. The test is no longer recommended in infertility evaluations [43].

Female: Ovarian Factor

The primary function of the ovaries is to produce a mature follicle that will release an egg, in a process called ovulation. Ovarian factor infertility is diagnosed when a woman does not ovulate, or experiences anovulation. This ovarian dysfunction accounts for $40 \%$ of female infertility [45]. There are several causes of ovarian factor infertility, and the World Health Organization categorizes ovulation disorders into three groups [46]. 
Group I consists of women who have hypogonadotropic (secondary) hypogonadism, which is most present in women of low BMI and women who exercise excessively [47]. These two factors lead to the reduced production of gonadotrophin releasing hormone by the hypothalamus, which then results in reduced production of luteinizing hormone $(\mathrm{LH})$ and follicle stimulating hormone (FSH) by the pituitary gland [47]. The lack of these hormones ultimately leads to the absence of menstruation, or amenorrhea [47].

Group II includes women of whom have hyperprolactinaemic amenorrhoea - or hyperprolactinaemia - or polycystic ovarian syndrome (PCOS). Hyperprolactinaemia results when the pituitary gland produces a reduced amount of $\mathrm{LH}$ and $\mathrm{FSH}$, caused by a microadenoma on the pituitary gland [47]. The next Group II diagnosis, PCOS, is present in $5-10 \%$ of reproductive aged women [46] and accounts for $70 \%$ of infertility due to anovulation [47]. PCOS arises when the ovary/ovaries produce an excess amount of androgen, which results in several pre-ovulatory follicles to be formed. When these follicles don't respond to $\mathrm{FSH}$, no dominant follicle is produced [47], and the multiple small follicles remain [46]. PCOS is most common in women in their late teens to early 20 s, and is often present with excessive hair growth (hirsutism), irregular periods, acne, and obesity [47].

Women in Group III are those women of whom have hypergonadatrophic (primary) hypogonadism, resulting in ovarian failure or premature menopause. Primary hypogonadism results from the ovaries not producing enough estrogen 
and producing higher levels of $\mathrm{LH}$ and FSH [48]. The resulting premature menopause makes the patient incapable of ovulating, and therefore, infertile.

Another ovarian factor that can lead to infertility not mentioned in the WHO classifications is diminished ovarian reserve. Diminished ovarian reserve refers to a reduced number of and/or reduced quality of oocytes in reproductive aged women who have regular menstruation [45]. Women with diminished ovarian reserve generally have lower serum antimüllerian hormone (AMH) concentrations, which is associated with poor response to ovarian stimulation and poor IVF pregnancy outcomes [45]. It should be noted however, that an AMH test with poor results does not imply the inability to conceive [45].

\section{Male Factor Infertility}

In reproduction, the role of the male is to have enough sperm ejaculated in order to fertilize the female's egg. Male factor infertility is solely responsible for $20 \%$ of infertile couples, and contributes to an additional $30-40 \%$ of infertile couples [49]. Most male infertility (90\%) is due to poor sperm quality, low sperm counts, or both [50]. Males with oligozoospermia present semen that consists of low sperm concentration and low sperm motility. Even more dramatic, azoospermia is when semen has absolutely no sperm. There are two ways azoospermia can be caused. Obstructive azoospermia is a result of blockage in the epididymis or the ejaculatory ducts, therefore preventing sperm to be present in the semen [51]. Non-obstructive azoospermia is caused by a testicular 
dysfunction, which is the leading cause of disturbed spermatogenesis [51]. Some cases of non-obstructive azoospermia can include hypergonadotrophic hypogonadism, which is characterized by higher concentrations of FSH being present [51]. Conversely, hypogonadotrophic hypogonadism, characterized by having lower concentrations of $\mathrm{FSH}$ and $\mathrm{LH}$, is caused by pituitary or hypothalamic diseases [51]. When a male presents with normal sperm, infertility could potentially be caused by ejaculatory problems, such as retrograde ejaculation and even the lack of ejaculation [49]. Further, there is evidence of male infertility having a fetal origin, either by genetic mutations leading to sexual development disorders, or by fetal chemical exposure leading to disruption of testes development [52].

\section{Unexplained Infertility}

The prevalence of unexplained infertility ranges from $8 \%$ to $37 \%$ [53]. Couples are diagnosed with unexplained infertility when both partners present with normal fertility evaluations, meaning that there is not one specific abnormality identified to be causing their infertility. Guidelines do exist on diagnosing unexplained infertility; the initial evaluation consists of a semen analysis, ovulation analysis, and evaluations of the uterine cavity and of tubal patency $[43,44]$. When all these evaluations return normal results, unexplained infertility is diagnosed to the couple. However, unexplained infertility prevalence, and even the existence of the term itself, remains debated. This is mainly because the process of diagnosing unexplained infertility, even with said 
guidelines, is questionable. Firstly, there still remain areas of reproductive science for which there are no testing procedures, meaning that a true infertility cause may not currently be possible of being diagnosed [53]. Further, when put to clinical practice, fertility evaluations vary widely among physicians and are not consistently executed, potentially leading to misdiagnosis [54]. Unexplained infertility can be a frustrating diagnosis to couples who are actively trying to conceive. Unlike the other diagnoses mentioned prior, there is no clear-cut answer to the problem, and therefore no clear-cut answer on how to approach treatment.

\section{Treatments for Infertility}

With so many causes of infertility, there is not a one-size-fits-all treatment. Certain infertility diagnoses qualify for some treatments over others. For example, some diagnoses may only require lifestyle changes to increase the likelihood of conception, while others may require assisted reproductive technology (ART). This section explores the varying infertility treatments, how they work, and which diagnoses are appropriate for each treatment. All information in this section can be referenced to the National Institute for Health and Care Excellence (NICE) Clinical Guidelines on infertility treatments [46].

Lifestyle Changes and Expectant Management 
Lifestyle changes are the preferred method of treatment for women of the Group I ovulation disorders. As mentioned in a prior section, secondary hypogonadism is present in women with low BMI or who exercise excessively. For these women, just increasing their BMI, normalizing their exercise, or both can increase their likelihood of conceiving.

Expectant management is the act of timing sexual intercourse with ovulation, and of increasing coital activity. Expectant management is the preferred method of treatment for couples that have an unexplained infertility diagnosis. It is recommended to these couples to try to conceive for at least 2 years with expectant management. If after 2 years of expectant management, these couples have still failed to conceive, then the couple is offered IVF treatment.

\section{Male Factor Treatments}

As mentioned prior, there are a number of etiologies for male factor infertility, of which the main treatment options consist of varying medical and surgical options, as well as IVF and ICSI, which will be discussed in a later section. For men with hypogonadotrophic hypogonadism, gonadotrophin drugs are offered. Men with obstructive azoospermia have the option to consider surgical repair of the blocked duct, but only as an alternative to sperm recovery and IVF. Ejaculatory disorders can be treated by a number of options, such as penile electrovibration and transrectal electroejaculation for anejaculation, 
varying drugs for retrograde ejaculation, and surgical sperm retrieval. IVF/ICSI are considered when all other treatments fail.

Assisted Reproductive Technologies: Ovulation Induction

Ovulation induction therapy is used for those with ovulatory disorders to help stimulate the ovaries to produce at least one egg, but usually more than one. There are several routes to induce ovulation, but they vary by ovulatory diagnosis. As mentioned prior, there are three groups of ovulation disorders. Of the three, ovulation induction can only be beneficial for those women in Groups I and II. For women with hypogonadatrophic hypogonadism (Group I), the first recommendation is to change their lifestyle factors, such as increasing their weight and BMI, as well as moderating strenuous exercise. Normalizing these lifestyle factors can increase their chances of ovulation and even conception. Doctors also offer these Group I women hormone pills to induce ovulation. For women with PCOS (Group II), those with a BMI greater than or equal to 30 are advised to lose weight, as lowering their BMI could restore their ovulation. For those without a severe BMI, it is recommended that hormone pills be offered, including an anti-oestrogen (clomiphene citrate), an insulin sensitizer (metformin hydrochloride), or a combination of both. Those women who do receive clomiphene citrate and/or metformin hydrochloride should not take the oral medication for longer than six months. 
Assisted Reproductive Treatments: Intrauterine Insemination

Intrauterine insemination (IUI) consists of inserting sperm directly into the uterine cavity around the time of ovulation. This treatment can be performed with or without ovulation induction. When ovulation induction is used, the insemination process does not occur until after the induction has occurred. Women take hormone tablets for several days. Then, if during an ultrasound, there is at least one, but no more than three developed follicles, induction occurs. Insemination then occurs within the next day to 36 hours.

In the past, IUI has been a treatment for the infertility diagnoses of mild endometriosis, mild male factor infertility, and unexplained infertility. However, the most recent NICE guidelines now recommend the following: 1) IUI with no ovulation induction should be given to those of whom cannot have vaginal intercourse, such as those with psychosexual disorders, same-sex couples, and those with conditions of which require special consideration (HIV positive males); 2) for those who have yet to conceive after 6 cycles of IUI, another 6 cycles of IUI without ovulation induction should be offered before offering IVF; and 3) for those with diagnoses of mild endometriosis, mild male factor infertility, and unexplained infertility, IUI should not be offered, but rather continue to attempt to conceive for at least two years before considering IVF.

Assisted Reproductive Treatments: In Vitro Fertilization and Intracytoplasmic Sperm Injection 
In Vitro Fertilization is an ART procedure that consists of the fertilization of eggs with sperm outside of the body. There are seven total stages of IVF, of which some are not always used. In general, the process consists of stimulating the female's ovulation, an ovulation trigger, egg and sperm retrieval, and embryo replacement. Stimulating ovulation results in eggs being produced, while ovulation trigger results in the initiation of ovulation. The eggs and sperm are then retrieved, and fertilization takes place in the laboratory. A few days after fertilization, the now embryos are placed in the female's uterus. Patients are sometimes offered hormones before ovulation stimulation and after embryo replacement to help with the preparation of the IVF process and with the early development of the embryo. In general, IVF acts as the last resort treatment option, only being used when the preferred treatment option for a diagnosis has failed. IVF is offered to patients of whom the following preferred methods have failed: 1) expectant management for unexplained diagnoses, 2) ovulation induction for ovarian disorders, 3) treatment of endometriosis, 4) treatment for tubal disease, and 5) treatment for identified male factor infertility. The infertility diagnoses that most warrant IVF, and of which IVF is the preferred treatment, are those of severe tubal disease and severe male factor.

Intracytoplasmic Sperm Injection is often used in tandem with IVF. ICSI involves the insertion of a single sperm into an egg during a typical IVF process. The benefit comes in selecting the specific sperm, usually the best individual sperm, that will fertilize the egg. For this reason, ICSI is mainly used when severe male infertility is involved, as the likelihood of fertilization in vitro is still 
very low. These disorders include low sperm quality and obstructive and nonobstructive azoospermia. ICSI is also an option for couples of other diagnoses of whom regular IVF has failed. However, ICSI with IVF only increases the likelihood of fertilization, and does not increase the overall conception rate any better than IVF alone.

\section{Infertility and Spontaneous Conception}

Couples who have infertility diagnoses can still sometimes conceive naturally, regardless of whether they have received ART. Among the literature of infertile couples, varying studies have found spontaneous conception rates to be anywhere from $11.2 \%$ to $80 \%[55,56]$. These rates, however, are sometimes crude rates, while other times are ongoing or cumulative rates. Also, studies vary highly in their defined population. For example, some studies only include patients that had prior live births from IVF or ICSI, while others include successful and unsuccessful treatments from ART, while still others only include those who had unsuccessful treatment or those of whom remain untreated. Spontaneous conception and live birth rates by study population are shown in Table 1. It is difficult to interpret these conception rates relative to the general infertile population, as each rate is very specific in its rate type and in its population. Further, some studies only report live birth rates; however, these rates can be thought of as the minimum conception rate, as there have to be at least as many conceptions as there are live birth. 
Table 1: Spontaneous Conception and Live Birth Rates Among Infertile Couples

\begin{tabular}{|c|c|c|c|c|c|}
\hline Population & Authors & Year & Outcome & Rate & $\mathbf{N}$ \\
\hline \multirow[b]{2}{*}{ currently receiving ART } & Vardon et al. & 1995 & \multirow{2}{*}{$\begin{array}{l}\text { spontaneous conception } \\
\text { first live birth from } \\
\text { spontaneous conception }\end{array}$} & $11.2 \%$ & 594 \\
\hline & Pinborg et al. & 2009 & & $18.2 \%$ & 817 \\
\hline $\begin{array}{c}\text { currently receiving ART with } \\
\text { unexplained infertility }\end{array}$ & Brandes et al. & 2011 & spontaneous conception & $60.2 \%$ & 437 \\
\hline \multirow{7}{*}{ prior successful ART } & Shimizu et al. & 1999 & $\begin{array}{l}\text { subsequent spontaneous } \\
\text { conception }\end{array}$ & $18.0 \%$ & 142 \\
\hline & Hennelly et al. & 2000 & $\begin{array}{l}\text { subsequent spontaneous } \\
\text { conception }\end{array}$ & $20.7 \%$ & 513 \\
\hline & Kupka et al. & 2003 & $\begin{array}{c}\text { subsequent spontaneous } \\
\text { conception }\end{array}$ & $80.0 \%$ & 32 \\
\hline & Ludwig et al. & 2008 & $\begin{array}{l}\text { subsequent spontaneous } \\
\text { conception }\end{array}$ & $20.0 \%$ & 695 \\
\hline & Troude et al. & 2012 & $\begin{array}{l}\text { subsequent live birth from } \\
\text { spontaneous conception }\end{array}$ & $17.0 \%$ & 1320 \\
\hline & Lande et al. & 2012 & $\begin{array}{l}\text { subsequent live birth from } \\
\text { spontaneous conception }\end{array}$ & $21.6 \%$ & 102 \\
\hline & Marcus et al. & 2016 & $\begin{array}{c}\text { subsequent spontaneous } \\
\text { conception }\end{array}$ & $27.3 \%$ & 307 \\
\hline \multirow{4}{*}{ prior unsuccessful ART } & Osmanagaoglu et al. & 2002 & $\begin{array}{l}\text { live births from spontaneous } \\
\text { conception }\end{array}$ & $11.5 \%$ & 200 \\
\hline & Kupka et al. & 2003 & spontaneous conception & $47.0 \%$ & 194 \\
\hline & Troude et al. & 2012 & $\begin{array}{l}\text { live births from spontaneous } \\
\text { conception }\end{array}$ & $24.0 \%$ & 814 \\
\hline & Marcus et al. & 2016 & $\begin{array}{l}\text { subsequent spontaneous } \\
\text { conception }\end{array}$ & $35.4 \%$ & 96 \\
\hline \multirow{3}{*}{ untreated by ART } & Collins et al. & 1995 & $\begin{array}{l}\text { live births from spontaneous } \\
\text { conception }\end{array}$ & $38.2 \%$ & 2198 \\
\hline & Snick et al. & 1997 & spontaneous conception & $72.0 \%$ & 342 \\
\hline & Eijkemans et al. & 2008 & spontaneous conception & $9.1 \%$ & 1034 \\
\hline
\end{tabular}


There are few studies in which the study population consists of infertile couples who remain untreated by ART. However, spontaneous conceptions rates among untreated women are relevant to this study, as $82(48.2 \%)$ of the LOUSSI study population used in this thesis never received any form of ART. Of the three studies of conception rates among untreated couples, two utilized Cox proportional hazards models. Resulting cumulative live birth rates were $38.2 \%$ at 36 months [57] and $72.0 \%$ at 36 months [58]. The median time to conceptions resulting in live births were 10.4 months and 8.1 months, respectively. The remaining study utilized a Kaplan-Meier method to determine a one-year cumulative pregnancy rate at $9.1 \%$ [59]. This would be equivalent to a $24.9 \%$ pregnancy rate after 36 months, assuming $9.1 \%$ rate per year. At first glance, these cumulative rates seem drastically different; however, cumulative pregnancy rates increase with time, so it does make sense that the shorter follow up will have the lowest cumulative rate.

The number of studies that assess spontaneous conception rates among infertile women who are actively, but inconsistently receiving ART is also limited. Among the three identified, one study found a $60.2 \%$ spontaneous conception rate in 5 years among women with unexplained infertility and currently receiving ART [9]. Conversely, a separate 5 -year prospective cohort study found the live birth rate following spontaneous conceptions to be $20.7 \%$ [60]. However, these births belonged to only $18.2 \%$ of the women in the study, meaning that some women spontaneously conceived and delivered twice within 5 years of initiating ART. An even more dramatically lower rate is found in a study that is written in a 
language other than English, but the abstract reports that this retrospective study found that $11.2 \%$ achieved a spontaneous conception among women in an IVF program [55]. However, the follow-up time is unknown. The 5-year spontaneous conception rates of these studies vary from $18.2 \%$ to $60.2 \%$. However, the highest conception rate was among women with an unexplained infertility diagnosis, which, as will be shown in a later section, is a diagnosis that usually results in the highest likelihood of conception.

Most literature regarding conceptions among infertile populations is conducted among those with prior successful ART treatment. Crude rates are most often reported, however, and the follow-up times vary in each study. For example, in one study with a two-year follow-up of women who had prior successful IVF/ICSI, 20.7\% had a subsequent spontaneous conception [3]. Another study, which included 7 to 9 years of follow up time, reported a cumulative live birth rate of $17 \%$ after a prior successful IVF/ICSI [8]. Further, an internet survey study included varying times of follow up and reported $27.3 \%$ spontaneous conception rate after successful IVF/ICSI [7]. This particular study, however, may be an overestimation of the true rate, as those women who did conceive are conceivably more likely to respond to the online survey. Other studies, with follow-up times between the aforementioned 2 and 9 years, report spontaneous conception or live birth rates after a successful IVF/ICSI treatment at $14.2 \%$ [56], $18 \%$ [6], 20\% [4], and $21.6 \%$ [5]. The literature on subsequent spontaneous conceptions after a successful IVF/ICSI treatment show rates between $14.2 \%$ and $27 \%$, with varying follow up times. When mentioned, the 
majority of spontaneous conceptions in all of these studies occurred within the first two years of follow up; this means that after having a successful IVF/ICSI, those who will achieve a subsequent spontaneous conception will most likely do so within the next two years.

Few studies can be identified that assess spontaneous conception rates after failed ART treatments. The internet study mentioned previously also analyzed spontaneous conceptions among women who had unsuccessful IVF/ICSI treatments and decided to discontinue treatments [7]. The authors report that $35.4 \%$ of these women achieved spontaneous conception. Another study included only women who were younger than 37 years, and reported a live birth (resulting from spontaneous conception) rate of $11.5 \%$ after discontinuing failed ICSI treatments [61]. Other studies have reported a $14.2 \%$ [56] spontaneous conception rate among those who discontinued IUI or IVF treatments, and a $24 \%$ [8] spontaneous conception rate after discontinuing unsuccessful IVF treatments. Although these studies reported on the same general population, spontaneous conception rates varied widely from $11.5 \%$ to $35.4 \%$. It should be noted, however, that the largest rate is reported in the internet survey study, which could potentially be an overestimation of the true spontaneous conception rate, as those women who did conceive would be more likely to respond than those who did not conceive.

\section{Predictors of Fertility}


There are a number of factors that are associated with overall fertility and the likelihood of conception. Accounting for these factors is imperative for comparing likelihoods of pregnancy across infertile groups. The purpose of this section is to review the literature on several important predictors of fertility that should be considered for inclusion in conception models.

\section{Obesity}

Overweight, or pre-obesity is defined by the CDC and the WHO as having a BMI between 25.0 to 29.9 , whereas obesity is defined as a BMI of 30.0 or greater [62, 63]. In the United States, roughly 32\% of women (ages 20 to 39 years) are obese. For reproductive-aged women, obesity can have major impacts on their fertility, including problems with ovulation, fertilization, and uterine problems.

One of the proposed mechanisms on how obesity can affect ovulation is through insulin resistance; having insulin resistance can lower the amount of sex hormone-binding globulins produced in the liver, resulting in increased amounts of free androgens and free estrogens. This increase of free estrogens ultimately leads to an increase of FSH released from the pituitary gland, which causes impaired ovulation [64]. It has also been shown that women who have irregular menses are four times more likely to be obese than women who have regular menses [65]. There also seems to be a dose-dependent relationship between the percentage of anovulatory cycles a woman has and her BMI; for women less 
than $20 \%$ overweight, $20-49 \%$ overweight, $50-74 \%$ overweight, and more than $74 \%$ overweight, the percent of anovulatory was $2.6,4.0,5.8$, and 8.4 , respectively [65]. The insulin resistance associated with obesity is also a main factor in the development of PCOS; as mentioned prior, PCOS is caused by excess androgen, leading to multiple follicles to be formed on the ovaries [47]. Further, one study found that women with PCOS were nearly twice as likely to be overweight than those women without PCOS, with rates of BMls of 25 or more at $60.6 \%$ and $34.8 \%$ ( $p$-value $<0.001)$, respectively [66].

Fertilization can also be a problem for obese women. One study found that among IVF recipients, women with a BMI between 35 and 39.9, and women with a BMI of 40 or higher, had significantly fewer normally fertilized oocytes (mean of 7.7 and 7.6, respectively), compared to the referent group women of BMI of 18.5 to 24.9 (mean of 9.3) (p-value < 0.03) [67]. The study also showed that when compared to women with a BMI between 18.5 and 24.9, women with BMls between 30 and 34.9 , between 35 and 39.9 , and 40 or greater had significantly lower odds of achieving conception on their first IVF cycle, with ORs of 0.67 (95\% Cl: $0.46-0.97), 0.56$ (95\% Cl: $0.34-0.93)$ and $0.50(95 \% \mathrm{Cl}: 0.31$ - 0.82), respectively [67]. There was also a clear dose-dependent relationship between odds of conception during the first IVF cycle and BMI, suggesting that an increasing BMI decreases the likelihood of fertilization.

Being obese can also have detrimental effects on the functioning of the uterus. One study found that among women receiving healthy donor eggs, a negative linear trend was found between implantation rates and higher BMI ( $p$ - 
value $=0.008$ ) [68]. Likewise, when comparing women with a BMI of 25 or greater with women of a BMI of less than 25 , those who were overweight had significantly lower odds of conceiving, with pregnancy rates of $38.3 \%$ and $45.5 \%$, respectively ( $p$-value $=0.002)$, and an OR of $0.85(95 \% \mathrm{Cl}: 0.76-0.95)$ [68].

Obesity can also affect the effectiveness of ART treatments. For instance, one study found that among women receiving ovulation induction, there was a significant correlation between weight and the needed dose for conception to occur ( $p$-value < 0.001) [69]. For women receiving IVF treatments, BMI has been shown to significantly decrease the odds of conception, with an OR of 0.843 (95\% Cl: $0.73-0.97)$ for a one-unit increase of BMI [70]. Likewise, a metaanalysis found that when comparing women with a BMI of 25 or greater to women with a BMl of less than 25 , those who were overweight had significantly lower odds achieving pregnancy $(\mathrm{OR}=0.71,95 \% \mathrm{Cl}: 0.62-0.81)[71]$.

Based on the evidence, it is clear that obesity negatively affects all aspects of fertility, including the efficacy of ART treatments. Lower BMI, at or below the normal range, can greatly increase the likelihood of both spontaneous and ART-related conception by resulting in healthy functioning reproductive organs and normal hormone levels.

\section{Smoking}

Cigarette smoking is well-known to be associated with a number of diseases, including infertility. However, $20.7 \%$ of reproductive aged women in the 
United States are smokers [72]. One meta-analysis found that women who were smokers had higher odds of experiencing infertility than those women who were not smokers $(\mathrm{OR}=1.60,95 \% \mathrm{Cl}: 1.34-1.91)$ [73]. Smoking has the ability to affect all facets of fertility, including ovarian and fallopian tube function, fertilization, embryo development, implantation, and even miscarriage $[74,75]$. It has been shown that when comparing age-matched smokers to non-smokers, ovarian reserve is significantly lower in the smokers ( $p$-value $<0.05)$, with an increased OR for diminished ovarian reserve of 2.8 (95\% Cl: $1.2-7.99)$ [76]. Smoking is also detrimental to fallopian tube functioning, causing a reduced blood flow [74] and an impaired ability to transfer oocytes [74, 75]. One study found that women who smoke more than 20 cigarettes per day had four times the odds of ectopic pregnancies, compared to women who had never smoked (OR= $3.9,95 \% \mathrm{Cl}: 2.6-5.9)$, concluding that transfer of oocytes to the uterus by the fallopian tubes is reduced due to cigarette smoking [77]. Implantation is also impaired as a result of smoking; in one study comparing light smokers $(0-10$ cigarettes per day) to heavy smokers ( $11-20$ cigarettes per day) using donor oocytes, the light smokers had a significantly higher pregnancy rate than the heavy smokers, with pregnancy rates of $52.2 \%$ and $34.1 \%$, respectively ( $p$-value $=0.02)[78]$. The results from this study showed that when using a healthy donor oocyte, implantation is higher among light smokers than heavy smokers.

Cigarette smoking can have a detrimental effect on conception success while receiving ART treatments. Two meta-analyses found associations between smoking and lowered ART conception rates. The first found that smokers had 
$33 \%$ lower odds of conceiving per IVF cycle than non-smokers (OR $=0.66,95 \%$ Cl: $0.49-0.88)[73]$. The second found that non-smokers had $79 \%$ higher odds of conceiving during the first IVF attempt than smokers $(\mathrm{OR}=1.79,95 \% \mathrm{Cl}: 1.24$ -2.59) [78]. Finally, another study showed via multivariable analysis, that women who have ever smoked had a higher risk of unsuccessful IVF (RR $=2.71,95 \%$ $\mathrm{Cl}: 1.37-5.25)$ [79]. This study also showed a dose-response to smoking, as each additional year of smoking increased the risk of having no pregnancy by $9 \%$ $(\mathrm{RR}=1.09,95 \% \mathrm{Cl}: 1.0-1.16)[79]$.

Based on the current evidence of smoking and infertility, it is clear that cigarette smoking is harmful to fertility through more than one pathway.

\section{Ovarian Reserve - Follicle Stimulating Hormone and AntiMüllerian Hormone Levels}

Ovarian reserve refers to a woman's potential to reproduce, as related to how many oocytes and the quality of the oocytes she contains [80]. Diminished ovarian reserve (DOR) refers to reproductive aged women of whom, when compared to other women of the same age, have lower ovarian stimulation and fecundity [80]. Follicle stimulating hormone (FSH) and antimüllerian hormone (AMH) are two measures that are often used to estimate ovarian reserve.

FSH levels vary throughout the menstrual cycle, and testing should occur between the first and fifth day; during this time, normal FSH levels are below 10 $\mathrm{mIU} / \mathrm{mL}$ [81]. However, increased FSH levels during this time indicate DOR [80]. 
In one longitudinal cohort study, 437 couples with unexplained infertility were followed between two and eight years, while observing for any pregnancy [9]. Of the 437 couples, only 81 couples did not conceive. When comparing those couples who did conceive against those couples who did not conceive, female FSH levels were significantly lower in those who did conceive ( $p$-value $=0.02$ ). However, in a study of older women of reproductive age (30 - 44 years), those with high serum and urinary FSH levels did not result in a significantly different pregnancy prediction after 6 cycles of attempt or after 12 cycles of attempt [82]. The contradicting results of whether FSH levels can predict pregnancy chances most likely comes from the efficacy of the FSH test, which is known to have a high specificity, but a low sensitivity [80]. However, the test is still used, as it has a high positive predictive value, regardless of its simultaneous low negative predictive value [80].

Levels of AMH vary throughout a woman's lifetime; levels rise in younger years, and typically peak around age 25 , after which, levels decline until becoming virtually zero a few years before menopause [80]. AMH is independent of the menstrual cycle and can therefore be tested at any day of the cycle [80]. Depending on the woman's age, normal AMH levels range between $0.5 \mathrm{ng} / \mathrm{mL}$ and $2.7 \mathrm{ng} / \mathrm{mL}$ [81]. Lowered AMH levels are clinically indicative of DOR. In one study of women receiving IVF/ICSI treatments, women who achieved live births as a result of treatment had significantly higher $\mathrm{AMH}$ levels than those women who did not achieve live births $(p-v a l u e=0.001)$ [83]. Likewise, in women receiving IUI treatments, those who achieved pregnancy had significantly higher 
$\mathrm{AMH}$ levels than those women who did not achieve pregnancy $(\mathrm{p}$-value $=\mathrm{P}=$ 0.0004) [84]. Clinically, AMH testing is the most relied-upon ovarian reserve testing, as it is the most sensitive and is capable of predicting ovarian response during ART treatments [80].

\section{Sexually Transmitted Infections}

STIs such as Chlamydia trachomatis (chlamydia) and Neisseria gonorrhoeae (gonorrhea) can contribute to reduced fertility in women. It is surprising, then, that to the best of my knowledge, no studies assessing characteristics associated with conception among infertile populations include STI history in their models. The STIs reviewed here are the only STIs reported in the medical histories of the participants of the current thesis.

\section{Chlamydia trachomatis}

The mechanism behind the association between Chlamydia trachomatis (chlamydia) and infertility is through pelvic inflammatory disease (PID). PID is an infection of the uterus, fallopian tubes, and pelvic structures, usually caused by surgery or pregnancy [10]. However, chlamydia is the major cause of PID that is not associated with pregnancy nor surgery [10], and is responsible for $50 \%$ of all PID cases [85]. PID increases the risk of tubal infertility; with one episode of PID, the relative risk of tubal infertility is roughly $10 \%$, and each repeat PID episode nearly doubles the risk of tubal infertility $[86,87]$. For example, women with two 
PID episodes have a $20 \%$ higher relative risk of tubal disease, and nearly a $40 \%$ higher relative risk after the third episode. Further, another study found associations between chlamydia antibodies and tubal factor infertility [88]. Another study found that among reproductive-aged women, those with chlamydia infection had significantly increased odds of infertility, nearly 10 times as high as those with no chlamydia infection (OR $=9.985,95 \% \mathrm{Cl}: 4.70-20.63)$ [11]. Likewise, it has also been shown that chlamydia antibodies are more frequent in women with infertility and tubal damage than in women with infertility and no tubal damage ( $p$-value $<0.0001)[16]$.

\section{Neisseria gonorrhoeae}

Similar to chlamydia, Neisseria gonorrhoeae (gonorrhea) can also cause PID [12]. However, gonorrhea is much less common in women with PID than is chlamydia [12], with only $10-19 \%$ of PID cases being attributed to gonorrhea infection [85]. Although gonorrhea infection can also lead to the same tubal factor infertility, tubal factor infertility is much more of a risk among those infected with chlamydia. One study found no significant difference of gonorrhea infection between women with infertility and tubal damage, and women with infertility and no tubal damage [16]. Similarly, another study found that women with gonorrheaassociated PID were much less likely to experience adverse fertility outcomes than those with chlamydia-associated PID [14]. 


\section{Human Papilloma Virus and Herpes Simplex Virus}

Though effects of HPV on infertility are well-established in males, there is little evidence demonstrating any effect of Human Papilloma Virus (HPV) and of Herpes Simplex Virus (HSV) on infertility in women $[17,18]$. It is established, however, that HPV infection in pregnant women can cause adverse pregnancy outcomes, such as miscarriage and the premature rupture of the membrane [18]. Similarly, the effect of HSV on male infertility is also well-established; however, HSV infection has no association with cervical factor infertility [19]. HSV may, however, be associated with PID, although this is not definitive [20].

\section{Caffeine}

Studies assessing the effects of caffeine on pregnancy have varying results, keeping the association between the two in current debate. Most studies of women receiving ART treatments show no association between caffeine and the likelihood of conception. One study found no linear trend between current caffeine consumption and pregnancy among women receiving IVF treatments ( $p$ value for trend $=0.74$ ) [89]. Two more studies report similar findings, with no association between current caffeine consumption and pregnancy among ART recipients [90], nor between caffeine consumption the year prior to treatments and pregnancy among ART recipients [91], even with the median caffeine consumption of $456 \mathrm{mg}$ per day and $125 \mathrm{mg}$ per day, respectively. Although studies among women receiving ART treatments report consistent findings, 
studies conducted among women not receiving ART treatments seem to report findings that are rather inconsistent. One study found that an increased number of cups of coffee per day ( $p$-value for trend $=0.003$ ), as well as an increased amount of caffeine per day ( $p$-value for trend $=0.001)$, had significant negative trends with increased time to pregnancy [92]. The study also found that women who consumed more than $500 \mathrm{mg}$ per day of caffeine were 1.45 times the odds $(95 \% \mathrm{Cl}: 1.03-2.04)$ to take at least 9.5 months to conceive than women who drank $100 \mathrm{mg}$ per day or less of caffeine [92]. However, another study conducted among women not receiving ART treatments found that, for increased caffeine consumption and achieving conception, the adjusted ORs suggested a general negative trend with increasing caffeine consumption; however, none of the ORs were significant, and therefore, there was no significant association between increased caffeine consumption and pregnancy [93].

The majority of evidence suggests that caffeine consumption has little to no effect on the likelihood of pregnancy. However, even with very few studies reporting associations, the association between caffeine and pregnancy cannot be entirely ruled out, but it should be noted that caffeine may be a proxy measure for other behaviors or dietary factors and residual confounding is likely a problem in most studies.

\section{Alcohol}


The effects of alcohol on pregnancy remain in question, as varying studies report conflicting results. Some report that there is a negative association between how much one drinks and her likelihood of pregnancy, while others report that there is no association.

In a case-control study of 20 to 40 year old women, no significant linear trend between increased number of drinks consumed per week and trouble achieving pregnancy was found [94]. There was also no association with pregnancy when separate drinks were analyzed; when compared to having no drinks per week, the ORs for having more than 5 drinks of wine, beer, and spirits was 1.16 (95\% Cl: $0.72-1.88), 1.06$ (95\% Cl: $0.82-1.37)$, and $1.44(95 \% \mathrm{Cl}$ : $0.84-1.64)$, respectively.

However, a longitudinal study of reproductive aged women did find significant associations between alcohol and conception when assessing the women who were non-smokers [93]. Women who drank 1 to 12 grams, $13-90$ grams, and greater than 90 grams of alcohol per week had less odds of conceiving than women who did not drink at all, with ORs of $0.43(95 \% \mathrm{Cl}$ : $0.25-$ $0.76), 0.40$ (95\% Cl: $0.21-0.77)$, and $0.28(95 \% \mathrm{Cl}: 0.20-2.15)$, respectively. Although the group of women who drank more than 90 grams of alcohol per week did not result in a significant result due to a small sample size within this group, the results do show a negative dose response relationship between how much a woman drinks and her likelihood of pregnancy.

Further, one study found significant associations between amount of alcohol consumed through the week and infertility diagnoses [95]. Moderate 
drinkers (100 grams or less) and heavy drinkers (more than 100 grams) had higher odds of having an ovulatory factor infertility diagnosis than nondrinkers, with ORs of $1.3(95 \% \mathrm{Cl}: 1.0-1.7)$ and $1.6(95 \% \mathrm{Cl}: 1.1-2.3)$, respectively. Similarly, moderate $(\mathrm{OR}=1.6,95 \% \mathrm{Cl}: 1.1-2.3)$ and heavy drinkers $(\mathrm{OR}=1.5$, $95 \% \mathrm{Cl} 0.8-2.7)$ had higher odds of having endometriosis as their infertility diagnosis than nondrinkers.

Although the exact relationship between alcohol consumption on conception is still under investigation, it is accepted that alcohol consumption is not beneficial for those who are trying to conceive. For this reason, and for the reason of conflicting literature, alcohol consumption should be included when modeling likelihood of conception.

\section{Primary vs. Secondary Infertility}

Most studies that analyze the likelihood of conception find no association with having at least one prior parity $[2,4,6,8,9,56,60]$. There are two studies, however, that found associations of parity and likelihood of conception. The first found that among infertile couples remaining untreated by ART, live birth rates were positively associated with secondary infertility $(\mathrm{HR}=1.83 ; 95 \% \mathrm{Cl}: 1.24-$ 2.69) [57]. Similarly, the next study found that untreated couples with primary infertility were achieving spontaneous conception slower than those couples with secondary infertility ( $\mathrm{HR}=0.71,95 \% \mathrm{Cl}: 0.56-0.90)$ [59]. Presumably, if a 
couple is fertile enough to conceive once, they should be more likely to conceive than couples who have failed to ever achieve conception.

\section{Duration of Infertility}

Several studies have found significant associations between how long a couple experiences infertility and the likelihood of conception and live births. Across these analyses, varying durations are compared to estimate likelihood of pregnancy. One study found that among untreated couples, when compared to those with at least 36 months of infertility, couples with less than 36 months of infertility were achieving live birth faster $(\mathrm{HR}=1.68,95 \% \mathrm{Cl}: 1.14-2.48)$ [57]. Another study found that among couples with unexplained infertility receiving ART treatments, the duration of infertility was significantly different between couples who achieved pregnancy and did not achieve pregnancy, with mean durations of 20.2 months and 24.6 months, respectively ( $p$-value $<0.001)$ [9]. Likewise, several other studies have shown that shorter durations of infertility are significantly associated with higher likelihoods of conception and delivery $[8,55$, $58,59,61]$, with one study having duration of infertility as the only significant predictor of spontaneous conception among women receiving IVF [55].

\section{Female age}

The age of the female is one of the strongest predictors of pregnancy. This is largely due to decline of function of the female reproductive system with 
increasing age. At the age of puberty, women embody 300,000 to 500,000 oocytes; at 37 years of age, only 25,000 oocytes; and roughly 1,000 at the age of 51 years [96]. The levels of FSH and AMH also change throughout a woman's life; gradually, FSH increases and AMH decreases with increased age [96]. As mentioned in a separate section, increased FSH levels are associated with lower pregnancy rates, as well as lower AMH levels [80]. The combination of fewer oocytes, increased FSH levels, and decreased $\mathrm{AMH}$ levels results in slow but significant decline of fecundity in women beginning around the age of 32 years, and decreases rapidly after the age of 37 years [96]. Several studies have found negative associations between female age and the likelihood of conception, either spontaneous or while receiving $\operatorname{ART}[3,4,6,8,9,56,57,59]$.

One retrospective study assessing subsequent spontaneous conceptions after successful or unsuccessful IVF/ICSI treatments found a negative association with female age and the likelihood of conception [8]. Among those with prior successful IVF/ICSI treatments, when compared to women less than 30 years of age, women between the ages of 35 and $39(\mathrm{OR}=0.30,95 \% \mathrm{Cl}$ : $0.18-0.49)$ and women 40 or older $(\mathrm{OR}=0.25,95 \% \mathrm{Cl} 0.07-0.86)$ had significantly less odds of spontaneously conceiving. Similarly, among women with prior unsuccessful IVF/ICSI treatments, compared to those less than 30 years of age, women between 30 and $34(\mathrm{OR}=0.50,95 \% \mathrm{Cl}: 0.31-0.82)$, between 35 and $39(\mathrm{OR}=0.24,95 \% \mathrm{Cl}: 0.14-0.43)$, and 40 or older $(\mathrm{OR}=$ $0.18,95 \% \mathrm{Cl}: 0.09-0.38$ ) had significantly less odds of spontaneously 
conceiving. Between both groups, a negative linear trend is present between female age and likelihood of spontaneous conception.

Similarly, a study of infertile couples that have remained untreated, by utilizing proportional hazards analysis, found that women less than 30 years old were $50 \%$ more likely to conceive than women 30 years old or older $(H R=1.50$, $95 \% \mathrm{Cl}: 1.05-2.16)$ [57]. A longitudinal study of couples with unexplained infertility found that women who achieved spontaneous conception were significantly younger than women who were not able to spontaneously conceive, with mean ages of 31.3 and 34.1 , respectively $(p=<0.001)$ [9].

The clinical and epidemiological evidence shows that increased female age results in decreased fecundity and decreased likelihood of conception. In models of likelihood of conception, female age should always be controlled for, and it is unsurprising when female age is significantly and negatively associated with likelihood of conception.

Infertility diagnosis

Between varying studies, certain infertility diagnoses may be more associated with the likelihood of conception than others. Several studies found that different infertility diagnoses have significantly different associations with spontaneous conception among varying populations of infertile couples, including a study [2] of infertile couples after IVF treatments, regardless of their success (p-value -0.024), and another study [3] of infertile couples after only successful 
IVF treatments $(p$-value $=0.0535)$. When studies do show significant differences in infertility diagnoses and conception or live birth rates, they do not consistently result in the same diagnoses being associated with conception. However, unexplained infertility seems to be the best diagnosis for likelihood of pregnancy.

\section{Unexplained}

Unexplained infertility seems to be the best diagnosis for likelihood of conception. A retrospective internet survey study found that among women who had discontinued IVF/ICSI, those with unexplained infertility were 2.82 times more likely to spontaneously conceive than those with tubal damage $(p=0.005)$ [7]. Another study found that among infertile couples who remained untreated by ART, those with unexplained infertility were more than twice as likely to spontaneously conceive than those with tubal infertility $(\mathrm{HR}=2.64,95 \% \mathrm{Cl}: 1.75$ - 3.98) [59]. Further, one study found that couples with prior unsuccessful IVF treatments and unexplained infertility are nearly 3 times higher odds of conception than couples with male factor infertility and prior unsuccessful IVF $(\mathrm{OR}=2.98,95 \% \mathrm{Cl}: 1.60-5.53)$ [8]. Several studies, with varying populations, report that unexplained infertility is the infertility diagnosis with the highest likelihood of conception or live birth [3, 5, 57, 59].

Male Factor 
In a study among untreated infertile couples, those with an infertility diagnoses of male defect were having live births at less than half the rate of those without a male defect diagnosis $(\mathrm{HR}=0.47,95 \% \mathrm{Cl}: 0.27-0.81)$ [57]. Interestingly, another study among untreated infertile couples found that couples with male factor infertility were spontaneously conceiving $57 \%$ faster than those with tubal factor infertility $(\mathrm{HR}=1.57,95 \% \mathrm{Cl}: 1.06-2.32)$ [59]. It should be noted that in these analyses, one compared male factor infertility to no male factor infertility, whereas the other compared male factor infertility to tubal factor infertility, which could explain the conflicting results, even with both studies among untreated infertile couples.

\section{Endometriosis}

Very little studies have found significant associations between endometriosis and the likelihood of conception. One follow-up study found that, among couples with prior live births from IVF/ICSI, those with an infertility diagnosis of endometriosis had the highest rate of subsequent spontaneous conception (28.3\% of diagnosed conceived) [3]. However, another study found that having endometriosis significantly lowered the time to spontaneous conception ( $\mathrm{HR}=0.39,95 \% \mathrm{Cl}: 0.18-0.85)$ among untreated infertile couples when compared to couples without an endometriosis diagnosis [57]. Again, the specific comparisons in each of these studies could be the reason behind the conflicting results. 


\section{Tubal Factor}

Few studies have found significant associations between tubal factor infertility and the likelihood of spontaneous conception or live birth, but those that do find significant associations only report negative associations. One study found that among untreated infertile couples, those with a tubal defect were spontaneously conceiving in half the time of those without a tubal defect $(\mathrm{HR}=$ $0.50,95 \% \mathrm{Cl}: 0.40-0.63)$ [57]. Similarly, another study of untreated infertile couples found that a tubal factor infertility diagnosis significantly decreased the likelihood of live birth after spontaneous conception (Relative likelihood $=0.14$, $95 \% \mathrm{Cl}: 0.06-0.33)$ when compared to those with no tubal diagnosis [58]. Further, another study found that among couples who had discontinued IVF treatments at least 3 years prior, those with tubal factor infertility were 7 times less likely to spontaneously conceive $(R R=0.13,95 \% \mathrm{Cl}: 0.03-0.52)$ when compared to those with a diagnosis of "other" (mostly ovulatory factors), with only $6.3 \%$ of those with tubal factor infertility achieving conception [2].

\section{Ovulation Factor}

Among the literature, ovulation factor infertility seems to be negatively associated with spontaneous conception. An internet survey study among women who had discontinued IVF or ICSI treatments found that those women with ovulation factor infertility had 2.58 times the odds ( $95 \% \mathrm{Cl}: 1.02-6.53)$ to 
conceive spontaneously when compared to the referent group of tubal infertility [7]. A study of untreated infertile couples found similar findings, with couples having a diagnosis of ovulation defect decreasing the likelihood of live birth after spontaneous conception (Relative likelihood $=0.35,95 \% \mathrm{Cl}: 0.21-0.58$ ) when compared to those with no ovulation defect [58]. Interestingly, however, one study reports that having an infertility diagnosis of "other" (which the authors say were mostly ovulatory diagnoses) had the highest rates of spontaneous conception among couples who had discontinued IVF treatments at least 3 years ago; $46.2 \%$ of women with the "other" diagnosis spontaneously conceived [2]. It is unknown, however, just how much of this group, containing only 13 couples, actually had an ovulatory factor diagnosis.

\section{PCOS}

Infertility diagnoses of PCOS are, to the best of my knowledge, not used in current models of conception among infertile couples; it is assumed that if PCOS diagnoses are included in these analyses, that it is part of an ovulatory factor diagnosis. However, the current thesis will include PCOS as its own diagnosis, as $39(22.6 \%)$ participants have a clinical PCOS diagnosis, and $48(27.9 \%)$ are self-reporting PCOS. As mentioned in prior sections, PCOS is a Group II ovarian factor infertility diagnosis, and accounts for $70 \%$ of infertility due to anovulation [47]. An excess of free androgen and a decrease FSH contribute to the formation of several pre-ovulatory follicles on the ovaries [47]. PCOS is associated with obesity, as obesity-related insulin resistance can lower the amounts of FSH and 
increase the amounts of androgens [64]. Women with PCOS are twice as likely to be overweight than women without PCOS [66].

\section{Male age}

Few studies utilize the male partner's age as predictors of likelihood of conception, and most of those that do find no association [8, 56, 57]. However, one longitudinal cohort study found that among 437 couples with unexplained infertility, those women who achieved pregnancy had partners of younger age than those women who did not conceive, with mean male ages of 33.3 and 35.9 , respectively ( $p$-value $<0.001$ ) [9].

\section{Sperm Volume and Sperm Motility}

In a fairly recent follow-up study of women who had a prior successful live birth as a result of IVF, those with partners of whom had higher concentrations of sperm volume were more likely to conceive ( $p$-value <0.01) [5]. Likewise, the women whose partners had higher sperm motility percentages were more likely to conceive ( $p$-value $<0.001)$. Another study of couples who had discontinued ART, found that women who did not conceive were significantly more likely to have partners with non-normal semen analyses than those women who did conceive spontaneously ( $p$-value $=0.03$ ) [56]. These results could be interpreted as infertility diagnosis; meaning that those couples with male factor infertility due to non-normal sperm motility and volume are less likely to conceive 
spontaneously than those couples without male factor infertility, which has been the result of prior mentioned papers $[3,57]$.

\section{Number of ART Treatments}

One retrospective study, of which utilized logistic regression, found that women who had prior successful IVF treatments, having 2 to 4 treatment attempts significantly decreased the odds of a subsequent live birth (OR compared to 1 attempt $=0.65,95 \% \mathrm{Cl}: 0.47-0.89$ ) [8]. Likewise, having 5 to 14 attempts significantly decreased the odds of subsequent spontaneous live birth (OR compared to 1 attempt $=0.44,95 \% \mathrm{Cl}: 0.23-0.82)$. Similarly, among women who had prior unsuccessful IVF treatments, having 2 to 4 IVF attempts (OR compared to 1 attempt: $0.39,95 \% \mathrm{Cl}: 0.26-0.60$ ) or 5 to 14 IVF attempts (OR compared to 1 attempt $=0.15,95 \% \mathrm{Cl}: 0.07-0.32$ ) significantly decreased the odds of subsequent spontaneous live birth. Among both the successful and unsuccessful IVF women, those who had only one attempt were more likely to have a live birth as a result of spontaneous conception. These results seem to suggest that those women of whom are fertile enough to conceive spontaneously, do not require treatments; whereas those who are not fertile enough to achieve spontaneous conception, would require several attempts. 


\section{METHODS}

\section{LOUSSI Study Recruitment and Baseline Data Collection}

For this thesis, data were used from the Louisville Tobacco Smoke Exposure, Genetic Susceptibility, \& Infertility Study (LOUSSI) (NICHD R15HS087911). The original purpose of the LOUSSI Study was to assess the effects of smoking habits and NAT2 genotype on fertility. Participants were recruited at the University of Louisville Reproductive Endocrinology and Infertility (REI) clinic between September 2016 and June $2018(\mathrm{~N}=264)$. A physician explained the purpose of the study to the patients and if the patient expressed interest, a LOUSSI team member explained the study in more detail. If the patient agreed, informed consent was obtained (IRB number: 16.0063) and a \$25 incentive was

extended. Exclusion criteria included being younger than 21 years of age, having an ongoing pregnancy, inability to communicate in English, and having no chance of achieving pregnancy i.e. hysterectomy, AMH levels nonexistent. Most participants gave a urine sample, which was used to assay cotinine levels and NAT2 genotype. All participants answered a smoking questionnaire to assess current and past exposure to tobacco smoke and other nicotine products. Demographic information and medical history (e.g., AMH levels, infertility diagnoses, STI history, ART treatments, conception data) was extracted from medical records. Baseline variables included age, BMI, race, blood pressure, age 
at menarche, smoking status/amount, alcohol use/amount, and drug use. All other variables were collected from patient history forms or medical records. Permission to recontact participants began at participant \#100.

\section{Follow-Up Data Collection}

Participants that gave permission for recontact were followed up with an email at least 6 months after enrolling into the LOUSSI Study. If not reached by email, participants were contacted by phone. For working phone numbers, up to 3 attempts were made to contact each participant by phone. Still, if contact was not made, they were mailed a paper questionnaire with a pre-addressed and prestamped return envelope. For those participants who were never recontacted, and for those of whom were never asked to be recontacted, pregnancy data was extracted from medical records.

Conception was defined as having achieved a clinical pregnancy by a positive pregnancy test, regardless of its outcome. The conception date was defined as the month after the last menstrual period as reported by the participants, or nine months before the due date as reported by the participant. From the medical records, the conception date was defined as either the conception date as recorded by the physician, or the month after the last menstrual period as recorded by the physician. ART treatments after initial enrollment were also extracted from medical records.

\section{Descriptive Statistics}


All statistics were determined by SAS Software (9.4). Three sub-samples were included for analysis: the total population, and the total population stratified by ART status (ever versus never). Descriptive statistics were analyzed in four ways, by which all variables were examined for an association with pregnancy (any versus none) in each of the three sub-samples, as well for an association with STI history (any versus none). Chi-square and Fisher's Exact test were reported; Fisher's Exact test was reported when the expected value was less than 5 for at least $25 \%$ of the cells. Significant associations were defined by a Chi-square or Fisher's Exact p-value of 0.05 or less.

\section{Etiologic Logistic Regression Modeling}

Treatment of variables for modeling are shown in Table 2. 
Table 2: Variable Definitions and Treatment in Modeling

\begin{tabular}{|c|c|}
\hline Variable & Categories (where applicable) \\
\hline Age & $\begin{array}{l}{ }^{*}<=32 \\
>=33\end{array}$ \\
\hline Obesity & $\begin{array}{l}{ }^{*} \mathrm{BMI}<30 \\
\mathrm{BMI}>=30\end{array}$ \\
\hline Race & Dummy variables \\
\hline *White & Yes/No \\
\hline Black & Yes/No \\
\hline Other & Yes/No \\
\hline Blood Pressure & $\begin{array}{l}\text { *Low: Systolic BP }<120 \text { and Diastolic BP }<80 \\
\text { Medium: Systolic BP between } 120-129 \text { and Diastolic BP }<80 \\
\text { High: Systolic BP }>=130 \text { and Diastolic BP }<89\end{array}$ \\
\hline Alcohol Use & Yes/*No \\
\hline \multicolumn{2}{|l|}{ Smoker } \\
\hline & $\begin{array}{l}\text { Smoker = cotinine level }>=100 \text { or self-report of smoking } \\
{ }^{*} \text { Non-Smoker }=\text { cotinine level }<100 \text { and no self-report of smoking }\end{array}$ \\
\hline $\ln (\mathrm{AMH})$ & Continuous \\
\hline Tubal Diagnosis & Yes/*No \\
\hline Uterine Diagnosis & Yes/*No \\
\hline Ovarian Diagnosis & Yes $/{ }^{*}$ No \\
\hline Male Diagnosis & Yes/*No \\
\hline PCOS Diagnosis & Yes/No \\
\hline History of STI & Yes/*No \\
\hline History of HPV & Yes/*No \\
\hline History of Chlamydia & Yes $/{ }^{*}$ No \\
\hline ART during Cycle & Yes/*No \\
\hline
\end{tabular}


To determine the effects of STI history on the likelihood of conception, logistic regression models were performed on the three sub-samples of the current population: 1 ) on the entire 170 women in the follow-up population; 2) on women who did not receive any ART treatment during the entire follow up; and 3) on women who received ART treatment at least once during the follow up. The dichotomous outcome for all models was pregnancy, with history of any STI being the main exposure of interest. Variables to be initially included in each model were chosen by a Chi-square or Fisher's Exact test $p$-value $<=0.2$ in the bivariable analysis with either STI history or pregnancy in the relevant population. For example, for a variable to be included in the model of women with no ART treatments, the variable had a $p$-value $<=0.2$ when compared to STI history or when compared to pregnancies among the sub-sample with no ART treatments. Because of the overwhelming evidence in the literature for the effects of older age and obesity on reduced fertility, age and obesity were included in all models, regardless of their descriptive statistic $p$-value.

Continuous variables were assessed for a dose-response by examining multiple categories' effects on the outcome. If a dose-response was found, then the variable was treated continuously. If a threshold effect was detected, similar categories were combined. Two-way interaction terms were tested in each model by including product terms. However, in all three models, all interactions were statistically non-significant, and therefore no interaction terms were kept in any model. 
A data-based method for assessing confounding was used. Confounders were defined as those variables that changed the OR for STI by more than $10 \%$ when removed from the model. Variables that were not confounders were examined for their effect on the precision of the effect of STI (i.e., the width of the $95 \%$ confidence interval for STI). If a variable removed from the model changed the OR of STI on pregnancy by less than $10 \%$, but increased precision, the variable was retained. Age and obesity were forced into the model due to the abundance of evidence of a strong association with fertility. Multicollinearity was tested several times throughout each modeling process by examining the variance decomposition proportions for all variables. Lastly, a HosmerLemeshow test was conducted on each of the final models to determine goodness of fit. Models were determined to be of good fit when the HosmerLemeshow test $p$-value was greater than 0.05 , of which all final models exhibited. AMH was log-transformed $(\operatorname{In}(\mathrm{AMH}))$ due to the skewed distribution of the variable.

Additionally, the variable for a uterine infertility diagnosis was not included in the testing of all models, as only nine participants had a uterine diagnosis. Likewise, the unknown diagnosis variable was excluded from the models of those who ever received ART, as only six participants in this sub-sample had this specific diagnosis.

\section{Predictive Logistic Regression Modeling}


To determine which factors were associated with the odds of pregnancy, predictive logistic regression models were performed, with pregnancy being the dichotomous outcome. Similar to the etiologic regression models, three predictive regression models were performed on the three sub-samples of the study. All variables were tested to determine their inclusion in the model, as well as several interaction terms. However, variables with a p-value of 0.2 or less were chosen to be initially included in the model, and after a stepwise analysis, those variables with a p-value of 0.2 or less were retained in the final model. Based on the evidence of a strong association with fertility, age and obesity were forced into each model, regardless of their respective p-values. Finally, a HosmerLemeshow goodness of fit test was performed on all final models, and models were determined to be of good fit if the test $p$-value was greater than 0.05 . Across all logistic regression analyses, significance is defined by a $p$-value of 0.05 or less.

It should also be noted that in two of the sub-samples, $\mathrm{AMH}$ levels were missing for 20 participants; for these two sub-samples, models were first tested with the $\mathrm{AMH}$ variable included to determine if $\mathrm{AMH}$ would be selected for the final model. Neither of the two models included AMH, so a second test was performed excluding the $\mathrm{AMH}$ variable, which resulted in final predictive models with larger sample sizes. For the third sample, those who ever received ART, all $\mathrm{AMH}$ values were present.

\section{Survival Analyses}


Follow-up data was used to determine the time to pregnancy. The start time was defined as the enrollment month of the participant - time 0 , whereas the end time was either 1) the last medical record entry, 2) the conception date, 3) the last contact with the participant, or 4) the last month that the participant was actively trying to achieve pregnancy. ART was included as a time-varying covariate.

Six separate survival analyses were conducted, respective to the six logistic regression performed: etiologic models with history of STI as the main exposure of interest among the three sub-samples, as well as predictive models among the three sub-samples. Variables to be included for testing in each survival analysis were those variables that were included in the final models of the respective logistic regressions. Across all survival analyses, significance is defined by a p-value of 0.05 or less.

The Proportional Hazards Assumption was assessed for each variable included in each of the six models. For those variables that violated the assumption, either by a correlation between Schoenfeld residual and time $p$ value of less than 0.05 or by examining their log-negative log curves, models were adjusted for the violating variable by either stratification or inclusion of an interaction term with time.

Time-varying data was used with ART per cycle (yes/no) being the timevarying covariate. In the two models produced for the sub-sample among those with no ART, the time-varying ART variable was not included; none of the women had ever received ART treatments, therefore none of the women had any value 
for ART other than 0 . However, in the models produced for the entire population and for the sub-sample of women who ever received ART, the time-varying ART variable was included, and hazard ratio estimates could be produced.

Among the four models in which the time-varying ART variable was included, determination of whether the ART variable met the Proportional Hazards assumption was tested by the production of an extended Cox model adjusting for all other covariates; if the ART*time variable had a significant $p$ value, it was considered to be significantly associated with time, and the final model was stratified by ART.

Kaplan-Meier survival curves were produced for all variables present in each model. Additionally, for each of the three etiologic models, adjusted survival curves were created for STI, controlling for all other variables in each model. 


\section{E. RESULTS}

Of the 264 participants in the entire LOUSSI cohort, follow-up data was successfully collected for 170 (64.4\%), either by extraction of medical records from a follow-up visit at the Fertility Clinic, and/or by direct recontact for those of whom permission was obtained (requested of participants 100-264) (Figure 1). 6 participants from the second group (numbers 100-264) declined to be recontacted; therefore, we obtained permission to recontact 157 people.

Figure 1: Flow Diagram for Participants with Follow-Up Information

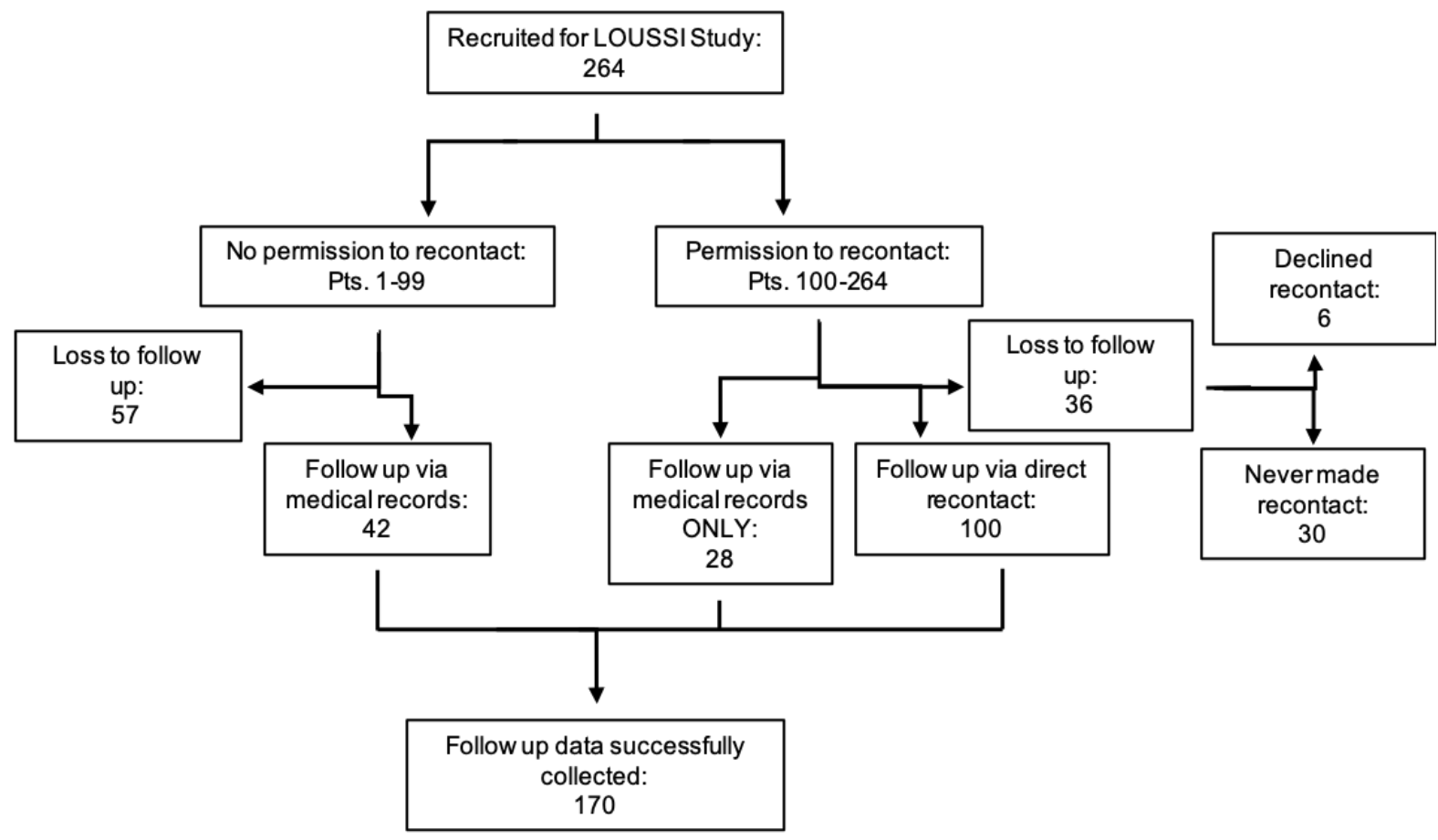

Of these 170 women, 82 (48.2\%) never received an ART treatment after enrolling in the LOUSSI Study, and $88(51.8 \%)$ received at least one cycle of 
ART treatment (Figure 2). There were 76 (44.7\%) women who achieved at least one pregnancy since enrollment. Among those women who never received ART, $32(39.0 \%)$ achieved a spontaneous pregnancy. Among those women who ever received ART, $44(50 \%)$ achieved a pregnancy, of which 35 (79.5\%) were through the means of ART, and 9 (20.5\%) were spontaneous conceptions.

Figure 2: Flow Diagram for the Three Sub-Samples of the Study

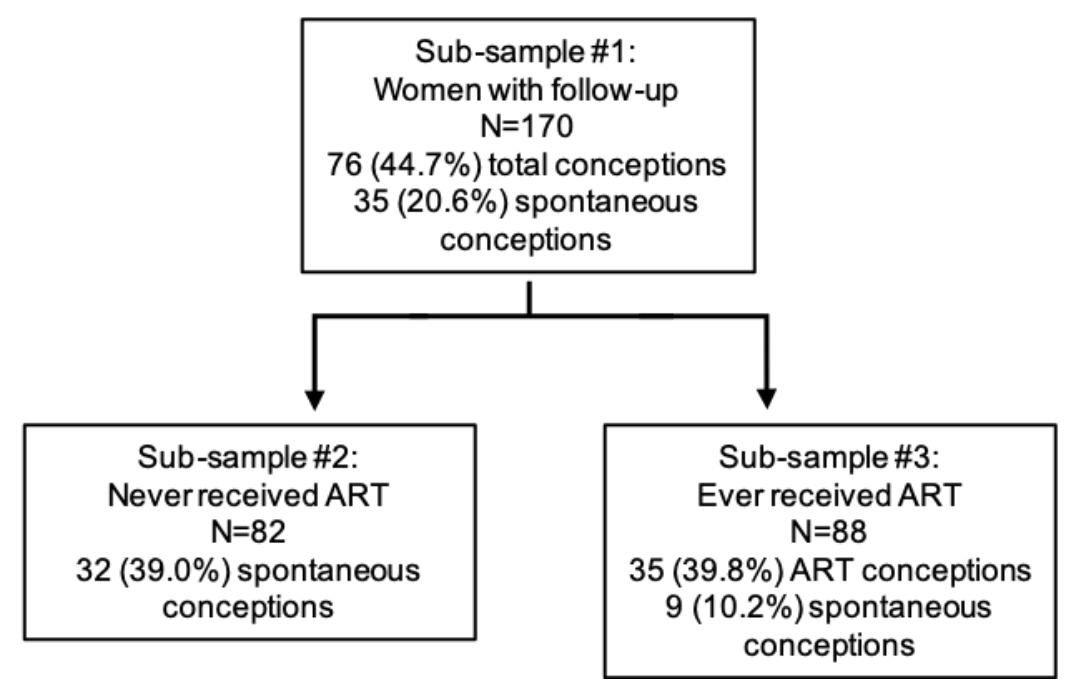

\section{Descriptive Statistics by Conception Status Among all Sub-Samples}

Table 3 shows the characteristics of all the women $(\mathrm{N}=170)$ included in this study stratified by pregnancy status (any vs. none). Those women who did achieve pregnancy were younger and less likely to be obese. However, these differences were not statistically significant. Women who achieved a pregnancy had lower cotinine levels $(P$-value $=0.019)$, had higher AMH levels $(P$-value $=$ $0.004)$, and were more likely to have an ovarian $(\mathrm{P}$-value $=0.024)$ or a PCOS (Pvalue $=0.041)$ infertility diagnosis than women who did not conceive. 
Table 3: Characteristics Among Entire Follow-Up Stratified by Conception Status ( $N=170)$

\begin{tabular}{|c|c|c|c|}
\hline & $\begin{array}{c}\text { Any } \\
\text { Conception } \\
N(\%) \\
N=76\end{array}$ & $\begin{array}{c}\text { No } \\
\text { Conception } \\
N(\%) \\
N=94\end{array}$ & $\begin{array}{c}\text { Chi- } \\
\text { Square } \\
\text { or Fisher } \\
\text { Exact } \\
\text { p-value }\end{array}$ \\
\hline Age & & & 0.398 \\
\hline$<=27$ & $24(31.58)$ & $20(21.28)$ & \\
\hline $28-32$ & $19(25.00)$ & $22(23.40)$ & \\
\hline $33-37$ & $19(25.00)$ & $30(31.91)$ & \\
\hline$>37$ & $14(18.42)$ & $22(23.40)$ & \\
\hline BMI & & & 0.219 \\
\hline$<18.5$ & $1(1.32)$ & $3(3.19)$ & \\
\hline $18.5-24.9$ & $20(26.32)$ & $18(19.15)$ & \\
\hline $25.0-29.9$ & $26(34.21)$ & $24(25.53)$ & \\
\hline$>=30$ & $29(38.16)$ & $49(52.12)$ & \\
\hline Race & & & 0.091 \\
\hline White & $46(60.53)$ & $50(53.19)$ & \\
\hline Black & $14(18.42)$ & $32(34.04)$ & \\
\hline Asian & $5(6.58)$ & $6(6.38)$ & \\
\hline Native American & $1(1.32)$ & $0(0.00)$ & \\
\hline Middle Eastern & $2(2.63)$ & $0(0.00)$ & \\
\hline Hispanic & $8(10.53)$ & $6(6.38)$ & \\
\hline Diastolic BP & & & 0.056 \\
\hline$<80$ & $45(59.21)$ & $53(56.38)$ & \\
\hline $80-89$ & $25(32.89)$ & $22(23.40)$ & \\
\hline$>=90$ & $6(7.89)$ & $19(20.21)$ & \\
\hline Systolic BP & & & 0.898 \\
\hline$<120$ & $33(43.42)$ & $38(40.43)$ & \\
\hline $120-129$ & $19(25.00)$ & $24(25.53)$ & \\
\hline $130-139$ & $17(22.37)$ & $20(21.28)$ & \\
\hline$>=140$ & $7(9.21)$ & $12(12.77)$ & \\
\hline Alcohol & & & 0.813 \\
\hline Yes & 35 (46.05) & $45(47.87)$ & \\
\hline No & 41 (53.95) & $49(52.12)$ & \\
\hline $\begin{array}{l}\text { Alcoholic Drinks } \\
\text { per Week }\end{array}$ & & & 0.581 \\
\hline 0 & $46(60.53)$ & $56(59.57)$ & \\
\hline $0-1$ & $12(15.79)$ & $20(21.28)$ & \\
\hline$>1$ & $18(23.68)$ & $18(19.15)$ & \\
\hline $\begin{array}{l}\text { Caffeine Drinks } \\
\text { per Day }\end{array}$ & & & 0.133 \\
\hline$<=1$ & 39 (51.32) & $59(62.77)$ & \\
\hline$>=2$ & 37 (48.68) & 35 (37.23) & \\
\hline
\end{tabular}


Self-Report

Smoker

$\begin{array}{lll}\text { Yes } & 10(13.16) & 19(20.21) \\ \text { No } & 66(86.84) & 75(79.79)\end{array}$

Packs per Day

$\begin{array}{ccc}0 & 66(86.84) & 75(79.79) \\ <1 & 5(6.58) & 13(13.83) \\ >=1 & 5(6.58) & 6(6.38)\end{array}$

Cotinine Level

(ng/mL)

$\begin{array}{ccc}<1 & 32(42.11) & 47(50.00) \\ 1-10 & 24(31.58) & 13(13.83) \\ >10 & 20(26.32) & 34(36.17)\end{array}$

AMH Level

(ng/mL)

$\begin{array}{ccc}<0.3 & 6(8.57) & 11(13.75) \\ 0.3-0.6 & 0(0.00) & 7(8.75) \\ 0.7-0.9 & 6(8.57) & 0(0.00) \\ 1-2.9 & 25(35.71) & 30(37.50) \\ >=3 & 33(47.14) & 32(40.00)\end{array}$

\section{Duration of}

Infertility

(months)

$\begin{array}{ccc}<12 & 32(42.11) & 42(44.68) \\ 13-24 & 17(22.37) & 16(17.02) \\ 25-48 & 9(11.84) & 13(13.83) \\ >=48 & 18(23.68) & 23(24.47)\end{array}$

Age at Menarche

(years)

7-10.9

$9(11.84) \quad 13(14.77)$

$11-12.9 \quad 26(34.21) \quad 32(36.36)$

13-14 $21(27.63) \quad 20(22.73)$

$>14 \quad 20(26.32) \quad 23(26.14)$

ART

Yes $\quad 44(57.89) \quad 44(46.81)$

No $\quad 32(42.11) \quad 50(53.19)$

Illicit Drug Use

Yes

No

$1(1.33) \quad 4(4.30)$

$74(98.67) \quad 89(95.70)$

Unexplained

Diagnosis

Yes

$12(15.79) \quad 19(20.21)$

No

64 (84.21) 75 (79.79)

Tubal Factor

Diagnosis

Yes $\quad 5(6.58) \quad 15(15.96)$

0.844

0.872

0.150

0.382

0.458

0.059 


\begin{tabular}{|c|c|c|c|}
\hline No & $71(93.42)$ & $79(84.04)$ & \\
\hline $\begin{array}{l}\text { Uterine } \\
\text { Diagnosis }\end{array}$ & & & 0302 \\
\hline Yes & $6(7.89)$ & $3(3.19)$ & \\
\hline No & $70(92.11)$ & $91(96.81)$ & \\
\hline $\begin{array}{l}\text { Ovarian } \\
\text { Diagnosis }\end{array}$ & & & 0.024 \\
\hline Yes & $21(27.63)$ & $13(13.83)$ & \\
\hline No & $55(72.37)$ & $81(86.17)$ & \\
\hline $\begin{array}{l}\text { Male Factor } \\
\text { Diagnosis }\end{array}$ & & & 0.148 \\
\hline Yes & $16(21.05)$ & $12(12.77)$ & \\
\hline No & $60(78.95)$ & $82(87.23)$ & \\
\hline PCOS Diagnosis & & & 0.041 \\
\hline Yes & $23(30.26)$ & $16(17.02)$ & \\
\hline No & $53(69.74)$ & 78 (82.98) & \\
\hline Other Diagnosis & & & 1.000 \\
\hline Yes & $1(1.32)$ & $2(2.13)$ & \\
\hline No & 75 (98.68) & $92(97.87)$ & \\
\hline $\begin{array}{l}\text { Unknown } \\
\text { Diagnosis }\end{array}$ & & & 0.230 \\
\hline Yes & $15(19.74)$ & $26(27.66)$ & \\
\hline No & $61(80.26)$ & $68(72.34)$ & \\
\hline History of STI & & & 0.902 \\
\hline Yes & $29(38.16)$ & 35 (37.23) & \\
\hline No & $47(61.84)$ & $59(62.77)$ & \\
\hline $\begin{array}{l}\text { History of } \\
\text { Chlamydia }\end{array}$ & & & 0.243 \\
\hline Yes & $13(17.11)$ & $23(24.47)$ & \\
\hline No & $63(82.89)$ & $71(75.53)$ & \\
\hline $\begin{array}{l}\text { History of } \\
\text { Gonorrhea }\end{array}$ & & & 0.132 \\
\hline Yes & $1(1.32)$ & $6(6.38)$ & \\
\hline No & $75(98.68)$ & $88(93.62)$ & \\
\hline History of HPV & & & 0.147 \\
\hline Yes & $14(18.42)$ & $10(10.64)$ & \\
\hline No & $62(81.58)$ & $84(89.36)$ & \\
\hline $\begin{array}{l}\text { History of } \\
\text { Herpes }\end{array}$ & & & 0.462 \\
\hline Yes & $2(2.63)$ & $5(5.32)$ & \\
\hline No & $74(97.37)$ & $89(94.68)$ & \\
\hline
\end{tabular}

Characteristics among women who never received ART treatments $(\mathrm{N}=82)$ are shown in Table 4. Among this sub-sample, women who achieved a 
pregnancy were younger and less obese, but again, not significantly. Women who did not achieve pregnancy had higher diastolic blood pressure. Those who achieved pregnancy were comparable to those who did not achieve pregnancy in all comparisons.

Table 4: Characteristics Among Those with No ART Stratified by Conception Status $(\mathrm{N}=82)$

\begin{tabular}{|c|c|c|c|}
\hline & $\begin{array}{c}\text { Any } \\
\text { Conception } \\
N(\%) \\
N=32\end{array}$ & $\begin{array}{c}\text { No } \\
\text { Conception } \\
N(\%) \\
N=50\end{array}$ & $\begin{array}{l}\text { Chi- } \\
\text { Square } \\
\text { or } \\
\text { Fisher } \\
\text { Exact } \\
\text { p-value }\end{array}$ \\
\hline Age & & & 0.428 \\
\hline$<=27$ & $14(43.75)$ & $14(28.00)$ & \\
\hline $28-32$ & $8(25.00)$ & $14(28.00)$ & \\
\hline $33-37$ & $5(15.63)$ & $14(28.00)$ & \\
\hline$>37$ & $5(15.63)$ & $8(16.00)$ & \\
\hline BMI & & & 0.150 \\
\hline$<18.5$ & $0(0.00)$ & $3(6.00)$ & \\
\hline $18.5-24.9$ & $9(28.13)$ & $13(26.00)$ & \\
\hline $25.0-29.9$ & $11(34.38)$ & $8(16.00)$ & \\
\hline$>=30$ & $12(52.00)$ & $26(52.00)$ & \\
\hline Race & & & 0.359 \\
\hline White & $14(43.75)$ & $25(50.00)$ & \\
\hline Black & $9(28.13)$ & $18(36.00)$ & \\
\hline Asian & $4(12.50)$ & $4(8.00)$ & \\
\hline Native American & $0(0.00)$ & $0(0.00)$ & \\
\hline Middle Eastern & $2(6.25)$ & $0(0.00)$ & \\
\hline Hispanic & $3(9.38)$ & $3(6.00)$ & \\
\hline Diastolic BP & & & 0.058 \\
\hline$<80$ & $21(65.63)$ & $28(56.00)$ & \\
\hline $80-89$ & $10(31.25)$ & $11(22.00)$ & \\
\hline$>=90$ & $1(3.13)$ & $11(22.00)$ & \\
\hline Systolic BP & & & 0.799 \\
\hline$<120$ & $16(50.00)$ & $21(42.00)$ & \\
\hline $120-129$ & $8(25.00)$ & $14(28.00)$ & \\
\hline $130-139$ & $6(18.75)$ & $9(18.00)$ & \\
\hline$>=140$ & $2(6.25)$ & $6(12.00)$ & \\
\hline Alcohol & & & 0.133 \\
\hline Yes & $10(31.25)$ & $24(48.00)$ & \\
\hline No & $22(68.75)$ & $26(52.00)$ & \\
\hline
\end{tabular}


Alcoholic

Drinks per

Week

0

0-1

$>1$

Caffeine Drinks

per Day

$$
\begin{aligned}
& <=1 \\
& >=2
\end{aligned}
$$

Self-Report

Smoker

Yes

No

Packs per Day

0

$<1$

$>=1$

Cotinine Level

(ng/mL)

$<1$
$1-10$
$>10$

AMH Level

(ng/mL)

$<0.3$
$0.3-0.6$
$0.7-0.9$
$1-2.9$
$>=3$

Duration of Infertility

(months)

$$
<12
$$

13-24

25-48

$>=48$

Age at

Menarche

(years)

$7-10.9$
$11-12.9$
$13-14$
$>14$

Illicit Drug Use

Yes

No

$$
\begin{array}{cc}
25(78.13) & 31(62.00) \\
3(9.38) & 9(18.00) \\
4(12.50) & 10(20.00)
\end{array}
$$

0.305

0.902

$19(59.38) \quad 29(58.00)$

$13(40.63) \quad 21(42.00)$

0.258

$7(21.88) \quad 16(32.00)$

$25(78.13) \quad 34(68.00)$

0.618

$25(78.13) \quad 34(68.00)$

$5(15.63) \quad 10(20.00)$

$2(6.25) \quad 6(12.00)$

0.480

$12(37.50) \quad 20(40.00)$

$7(21.88) \quad 6(12.00)$

$13(40.63) \quad 24(48.00)$

0.514

$4(15.38) \quad 6(16.67)$

$0(0.00) \quad 0(0.00)$

$2(7.69) \quad 0(0.00)$

9 (34.62) $\quad 14(38.89)$

$11(42.31) \quad 16(44.44)$

0.268

$14(43.75) \quad 21(42.00)$

$9(28.13) \quad 10(20.00)$

$6(18.75) \quad 6(12.00)$

$3(9.38) \quad 13(26.00)$

0.968

$6(18.75) \quad 8(17.02)$

$11(34.38) \quad 16(34.04)$

$7(21.88) \quad 9(19.15)$

$8(25.00) \quad 14$ (29.79)

0.644

1 (3.23) $\quad 4(8.16)$

30 (96.77) $\quad 45$ (91.84) 


\begin{tabular}{|c|c|c|c|}
\hline $\begin{array}{l}\text { Unexplained } \\
\text { Diagnosis }\end{array}$ & & & 0.396 \\
\hline Yes & $1(3.13)$ & $5(10.00)$ & \\
\hline No & $31(96.88)$ & $45(90.00)$ & \\
\hline $\begin{array}{l}\text { Tubal Factor } \\
\text { Diagnosis }\end{array}$ & & & 0.114 \\
\hline Yes & $2(6.25)$ & $10(20.00)$ & \\
\hline No & 30 (93.75) & $40(80.00)$ & \\
\hline Uterine & & & \\
\hline Diagnosis & & & 1.000 \\
\hline Yes & $1(3.13)$ & $2(4.00)$ & \\
\hline No & $31(96.88)$ & $48(96.00)$ & \\
\hline $\begin{array}{l}\text { Ovarian } \\
\text { Diagnosis }\end{array}$ & & & 0280 \\
\hline Yes & $9(28.13)$ & $9(18.00)$ & \\
\hline No & $23(71.88)$ & $41(82.00)$ & \\
\hline Male Factor & & & \\
\hline Diagnosis & & & 0.144 \\
\hline Yes & $6(18.75)$ & $3(6.00)$ & \\
\hline No & $26(81.25)$ & $47(94.00)$ & \\
\hline $\begin{array}{l}\text { PCOS } \\
\text { Diagnosis }\end{array}$ & & & 0.316 \\
\hline Yes & $8(25.00$ & $8(16.00)$ & \\
\hline No & $24(75.00)$ & $42(84.00)$ & \\
\hline $\begin{array}{l}\text { Other } \\
\text { Diagnosis }\end{array}$ & & & 1.000 \\
\hline Yes & $0(0.00)$ & $1(2.00)$ & \\
\hline No & $32(100)$ & $49(98.00)$ & \\
\hline $\begin{array}{l}\text { Unknown } \\
\text { Diagnosis }\end{array}$ & & & 0.876 \\
\hline Yes & $14(43.75)$ & $21(42.00)$ & \\
\hline No & $18(56.25)$ & $29(58.00)$ & \\
\hline History of STI & & & 0.891 \\
\hline Yes & $12(37.50)$ & $18(36.00)$ & \\
\hline No & $20(62.50)$ & $32(64.00)$ & \\
\hline $\begin{array}{l}\text { History of } \\
\text { Chlamydia }\end{array}$ & & & 0.723 \\
\hline Yes & $6(18.75)$ & $11(22.00)$ & \\
\hline No & $26(81.25)$ & $39(78.00)$ & \\
\hline $\begin{array}{l}\text { History of } \\
\text { Gonorrhea }\end{array}$ & & & 1.000 \\
\hline Yes & $1(3.13)$ & $3(6.00)$ & \\
\hline No & $31(96.88)$ & $47(94.00)$ & \\
\hline History of HPV & & & 0.674 \\
\hline Yes & $3(9.38)$ & $3(6.12)$ & \\
\hline No & $29(90.63)$ & $47(94.00)$ & \\
\hline
\end{tabular}




\begin{tabular}{cccc}
$\begin{array}{l}\text { History of } \\
\text { Herpes }\end{array}$ & & & 0.396 \\
Yes & $1(3.13)$ & $5(10.00)$ & \\
No & $31(96.88)$ & $45(90.00)$ & \\
\hline
\end{tabular}

Table 5 displays the characteristics among women who ever received ART ( $N=88)$ after enrollment. Similar to the other sub-samples, those who achieved pregnancy were generally younger and less obese, but not significantly. Those who did become pregnant had significantly higher AMH levels $(\mathrm{P}$-value $=$ $0.005)$ and were significantly more likely to have an ovarian infertility diagnosis $(P$-value $=0.027)$

Table 5: Characteristics Among Those with ART Stratified by Conception Status $(\mathrm{N}=88)$

\begin{tabular}{|c|c|c|c|}
\hline & $\begin{array}{c}\text { Any } \\
\text { Conception } \\
\mathrm{N}(\%) \\
\mathrm{N}=44\end{array}$ & $\begin{array}{c}\text { No } \\
\text { Conception } \\
N(\%) \\
N=44\end{array}$ & $\begin{array}{c}\text { Chi- } \\
\text { Square } \\
\text { or } \\
\text { Fisher } \\
\text { Exact } \\
\text { p-value }\end{array}$ \\
\hline Age & & & 0.441 \\
\hline$<=27$ & $10(22.73)$ & $6(13.64)$ & \\
\hline $28-32$ & $11(25.00)$ & $8(18.18)$ & \\
\hline $33-37$ & $14(31.82)$ & $16(36.36)$ & \\
\hline$>37$ & $9(20.45)$ & $14(31.82)$ & \\
\hline BMI & & & 0.242 \\
\hline$<18.5$ & $1(2.27)$ & $0(0.00)$ & \\
\hline $18.5-24.9$ & $11(25.00)$ & $5(11.36)$ & \\
\hline $25.0-29.9$ & $15(34.09)$ & $16(36.36)$ & \\
\hline$>=30$ & $17(52.27)$ & $23(52.27)$ & \\
\hline Race & & & 0.090 \\
\hline White & 32 (72.73) & $25(56.82)$ & \\
\hline Black & $5(11.36)$ & $14(31.82)$ & \\
\hline Asian & $1(2.27)$ & $2(4.55)$ & \\
\hline Native American & $1(2.27)$ & $0(0.00)$ & \\
\hline Middle Eastern & $0(0.00)$ & $0(0.00)$ & \\
\hline Hispanic & $5(11.36)$ & $3(6.82)$ & \\
\hline Diastolic BP & & & 0.515 \\
\hline$<80$ & $24(54.55)$ & $25(56.82)$ & \\
\hline $80-89$ & $15(34.09)$ & $11(25.00)$ & \\
\hline$>=90$ & $5(11.36)$ & $8(18.18)$ & \\
\hline
\end{tabular}


Systolic BP

$\begin{array}{ccc}<120 & 17(38.64) & 17(38.64) \\ 120-129 & 11(25.00) & 10(22.73) \\ 130-139 & 11(25.00) & 11(25.00) \\ >=140 & 5(11.36) & 6(13.64)\end{array}$

0.987

Alcohol

Yes

No

Alcoholic Drinks per Week

\section{0}

0-1

$>1$

Caffeine Drinks

per Day

$$
\begin{aligned}
& <=1 \\
& >=2
\end{aligned}
$$

Self-Report

Smoker

$$
\text { Yes }
$$

Packs per Day

0

$<1$

$>=1$

Cotinine Level

(ng/mL)

$<1$
$1-10$
$>10$

AMH Level

( $\mathrm{ng} / \mathrm{mL}$ )

$$
\begin{gathered}
<0.3 \\
0.3-0.6 \\
0.7-0.9 \\
1-2.9 \\
>=3
\end{gathered}
$$

Duration of Infertility

(months)

$$
\begin{gathered}
<12 \\
13-24 \\
25-48 \\
>=48
\end{gathered}
$$

$\begin{array}{ll}21(47.73) & 25(56.82) \\ 9(20.45) & 11(25.00)\end{array}$

$24(54.55) \quad 14(31.82)$$$
41 \text { (93.18) } \quad 41 \text { (93.18) }
$$

41 (93.18) 41 (93.18)

Age at Menarche

(years)
25 (56.82) 21 (47.73)

19 (43.18) $23(52.27)$

$14(31.82) \quad 8(18.18)$

$20(45.45) \quad 30(68.18)$

$$
3(6.82) \quad 3(6.82)
$$

$0(0.00) \quad 3(6.82)$

$3(6.82) \quad 0(0.00)$

$20(45.45) \quad 27(61.36)$

$17(38.64) \quad 7(15.92)$

$7(15.91) \quad 10(22.73)$

$2(4.55) \quad 5(11.36)$

$0(0.00) \quad 7(15.91)$

4 (9.09) $\quad 0(0.00)$

$16(36.36) \quad 16(36.36)$

$22(50.00) \quad 16(36.36)$

0.393

0.336

0.031

1.000

0.058

0.057

0.005

0.374

$18(40.91) \quad 21(47.73)$

$8(18.18) \quad 6(13.64)$

3 (6.82) $7(15.91)$

$15(34.09) \quad 10(22.73)$

0.742 


$\begin{array}{ccc}7-10.9 & 3(6.82) & 5(12.20) \\ 11-12.9 & 15(34.09) & 16(39.02) \\ 13-14 & 14(31.82) & 11(26.83) \\ >14 & 12(27.27) & 9(21.95)\end{array}$

Illicit Drug Use

$\begin{array}{lll}\text { Yes } & 0(0.00) & 0(0.00) \\ \text { No } & 44(100) & 44(100)\end{array}$

\section{Unexplained}

Diagnosis

Yes
No

$$
\begin{array}{ll}
11(25.00) & 14(31.82) \\
33(75.00) & 30(68.18)
\end{array}
$$

Tubal Factor

\section{Diagnosis}

Yes

Uterine No

Diagnosis

Yes

No

Ovarian

Diagnosis

Yes

No

Male Factor

Diagnosis

Yes

No

PCOS Diagnosis

Yes

No

Other Diagnosis

Yes

No

Unknown

Diagnosis

Yes

No

History of STI

Yes

No

History of

Chlamydia

Yes

No

History of

Gonorrhea

$$
3(6.82) \quad 5(11.36)
$$

41 (93.18) 39 (88.64)

0.713

0.202

$5(11.36) \quad 1(2.27)$

$39(88.64) \quad 43(97.73)$

0.027

$12(27.27) \quad 4$ (9.09)

$32(72.73) \quad 40(90.91)$

0.796

$10(22.73) \quad 9(20.45)$

$34(77.27) \quad 35(79.55)$

15 (34.09) $8(18.18)$

$29(65.91) \quad 36(81.82)$

1.000

$1(2.33) \quad 1(2.22)$

$42(97.67) \quad 44$ (97.78)

0.089

0.202

$1(2.27) \quad 5(11.36)$

43 (97.73) $\quad 39(88.64)$

1.000

17 (39.53) $\quad 17$ (39.53)

$27(60.47) \quad 27(60.47)$

0.195

$7(15.91) \quad 12(27.27)$

37 (84.09) $\quad 32(72.73)$ 


\begin{tabular}{cccc} 
Yes & $0(0.00)$ & $3(6.82)$ & \\
No & $44(100)$ & $41(93.18)$ & \\
$\begin{array}{c}\text { History of HPV } \\
\text { Yes }\end{array}$ & $11(25.00)$ & $7(15.91)$ & 0.291 \\
No & $33(75.00)$ & $37(84.09)$ & \\
$\begin{array}{c}\text { History of } \\
\text { Herpes }\end{array}$ & & & 1.000 \\
Yes & $1(2.27)$ & $0(0.00)$ & \\
No & $43(97.73)$ & $44(100)$ & \\
\hline
\end{tabular}

\section{Descriptive Statistics by STI Status}

Among the total sample of 170 women, $64(37.6 \%)$ had a history of any STI, whereas 106 (62.4\%) had no history of any STI. The 64 with a history of any STI consisted of 36 chlamydia infections, 7 gonorrhea infections, 24 HPV infections, and 7 herpes infections, totaling 74 past STI infections (some participants had a history of more than one STI). Among these 64 women, 29 (45.3\%) achieved a pregnancy, $12(41.4 \%)$ of which were women who never received ART and 17 (58.6\%) of which had received ART.

In Table 6, characteristics of the entire sample stratified by STI history is shown. Those with a history of STI were more likely to be non-white $(\mathrm{P}$-value $=$ $0.013)$ and consume alcohol $(P$-value $=0.002)$. Additionally, those with a history of STI were more likely to have a tubal infertility diagnosis ( $P$-value $=0.028)$, but less likely to have an ovarian infertility diagnosis $(P$-value $=0.022)$.

Table 6: Characteristics Among Entire Follow-Up Stratified by History of STI $(\mathrm{N}=170)$

\begin{tabular}{|c|c|c|c|}
\hline & $\begin{array}{c}\text { History of } \\
\text { Any STI } \\
N(\%) \\
N=64\end{array}$ & $\begin{array}{c}\text { No History } \\
\text { of STI } \\
N(\%) \\
N=106\end{array}$ & $\begin{array}{c}\text { Chi-Square } \\
\text { or Fisher } \\
\text { Exact } \\
\text { p-value }\end{array}$ \\
\hline Age & & & 0.413 \\
\hline$<=27$ & $12(18.75)$ & $32(30.19)$ & \\
\hline
\end{tabular}




\begin{tabular}{|c|c|c|c|}
\hline $28-32$ & $16(25.00)$ & $25(23.58)$ & \\
\hline $33-37$ & $21(32.81)$ & $28(26.42)$ & \\
\hline$>37$ & $15(23.44)$ & $21(19.81)$ & \\
\hline BMI & & & 0.969 \\
\hline$<18.5$ & $1(1.56)$ & $3(2.83)$ & \\
\hline $18.5-24.9$ & $14(21.88)$ & $24(22.64)$ & \\
\hline $25.0-29.9$ & $18(28.13)$ & $32(30.19)$ & \\
\hline$>=30$ & $31(48.44)$ & $47(44.34)$ & \\
\hline Race & & & 0.013 \\
\hline White & $31(48.44)$ & $65(61.32)$ & \\
\hline Black & $27(42.19)$ & $19(17.92)$ & \\
\hline Asian & $3(4.69)$ & $8(7.55)$ & \\
\hline Native American & $0(0.00)$ & $1(0.94)$ & \\
\hline Middle Eastern & $0(0.00)$ & $2(1.89)$ & \\
\hline Hispanic & $3(4.69)$ & $11(10.38)$ & \\
\hline Diastolic BP & & & 0.897 \\
\hline$<80$ & $36(56.25)$ & $62(58.49)$ & \\
\hline $80-89$ & 19 (29.69) & $28(26.42)$ & \\
\hline$>=90$ & $9(14.06)$ & $16(15.09)$ & \\
\hline Systolic BP & & & 0.750 \\
\hline$<120$ & $26(40.63)$ & $45(42.45)$ & \\
\hline $120-129$ & 19 (29.69) & $24(22.64)$ & \\
\hline $130-139$ & $13(20.31)$ & $24(22.64)$ & \\
\hline$>=140$ & $6(9.38)$ & $13(12.26)$ & \\
\hline Alcohol & & & 0.002 \\
\hline Yes & $40(62.50)$ & $40(37.74)$ & \\
\hline No & $24(37.50)$ & $66(62.26)$ & \\
\hline $\begin{array}{l}\text { Alcoholic Drinks } \\
\text { per Week }\end{array}$ & & & 0.055 \\
\hline 0 & $31(48.44)$ & $71(66.98)$ & \\
\hline $0-1$ & $15(23.44)$ & $17(16.04)$ & \\
\hline$>1$ & $18(28.13)$ & $18(16.98)$ & \\
\hline $\begin{array}{l}\text { Caffeine Drinks } \\
\text { per Day }\end{array}$ & & & 0.775 \\
\hline$<=1$ & $36(56.25)$ & $62(58.49)$ & \\
\hline$>=2$ & $28(43.75)$ & $44(41.51)$ & \\
\hline $\begin{array}{l}\text { Self-Report } \\
\text { Smoker }\end{array}$ & & & 0.086 \\
\hline Yes & $15(23.44)$ & $14(13.21)$ & \\
\hline No & $49(76.56)$ & 92 (86.79) & \\
\hline Packs per Day & & & 0.151 \\
\hline 0 & $49(76.56)$ & $92(86.79)$ & \\
\hline$<1$ & $8(12.50)$ & $10(.43)$ & \\
\hline$>=1$ & 7 (10.94) & $4(3.77)$ & \\
\hline $\begin{array}{l}\text { Cotinine Level } \\
\text { (ng/mL) }\end{array}$ & & & 0.524 \\
\hline
\end{tabular}




\begin{tabular}{|c|c|c|c|}
\hline$<1$ & $31(48.44)$ & $48(45.28)$ & \\
\hline $1-10$ & $11(17.19)$ & $26(24.53)$ & \\
\hline$>10$ & 22 (34.38) & $32(30.19)$ & \\
\hline $\begin{array}{l}\text { AMH Level } \\
(\mathrm{ng} / \mathrm{mL})\end{array}$ & & & 0.228 \\
\hline$<0.3$ & $3(5.36)$ & $14(14.89)$ & \\
\hline $0.3-0.6$ & $2(3.57)$ & $5(5.32)$ & \\
\hline $0.7-0.9$ & $4(7.14)$ & $2(2.13)$ & \\
\hline $1-2.9$ & $23(41.07)$ & 32 (34.04) & \\
\hline$>=3$ & $24(42.86)$ & 41 (43.62) & \\
\hline $\begin{array}{l}\text { Duration of } \\
\text { Infertility } \\
\text { (months) }\end{array}$ & & & 0.381 \\
\hline$<12$ & $30(46.88)$ & $44(41.52)$ & \\
\hline $13-24$ & $10(15.63)$ & $23(21.70)$ & \\
\hline $25-48$ & $11(17.19)$ & $11(10.38)$ & \\
\hline$>=48$ & $12(20.31)$ & $28(26.42)$ & \\
\hline $\begin{array}{l}\text { Age at Menarche } \\
\text { (years) }\end{array}$ & & & 0.475 \\
\hline $7-10.9$ & $6(9.52)$ & $16(15.84)$ & \\
\hline $11-12.9$ & $26(41.27)$ & 32 (31.68) & \\
\hline $13-14$ & $14(22.22)$ & 27 (26.73) & \\
\hline$>14$ & $17(26.98)$ & $26(25.74)$ & \\
\hline ART & & & 0.783 \\
\hline Yes & $34(53.13)$ & $54(50.94)$ & \\
\hline No & $30(46.88)$ & $52(49.06)$ & \\
\hline Illicit Drug Use & & & 0.359 \\
\hline Yes & $3(4.84)$ & $2(1.89)$ & \\
\hline No & $59(95.16)$ & 104 (98.11) & \\
\hline $\begin{array}{l}\text { Unexplained } \\
\text { Diagnosis }\end{array}$ & & & 0.586 \\
\hline Yes & $13(20.13)$ & $18(16.98)$ & \\
\hline No & 51 (79.69) & $88(83.02)$ & \\
\hline $\begin{array}{l}\text { Tubal Factor } \\
\text { Diagnosis }\end{array}$ & & & 0.028 \\
\hline Yes & $12(18.75)$ & $8(7.55)$ & \\
\hline No & $52(81.25)$ & 98 (92.45) & \\
\hline $\begin{array}{l}\text { Uterine } \\
\text { Diagnosis }\end{array}$ & & & 0.730 \\
\hline Yes & $4(6.25)$ & $5(4.72)$ & \\
\hline No & $60(93.75)$ & $101(95.28)$ & \\
\hline $\begin{array}{l}\text { Ovarian } \\
\text { Diagnosis }\end{array}$ & & & 0.022 \\
\hline Yes & 7 (10.94) & $27(25.47)$ & \\
\hline No & 57 (89.06) & 79 (74.53) & \\
\hline $\begin{array}{l}\text { Male Factor } \\
\text { Diagnosis }\end{array}$ & & & 0.278 \\
\hline
\end{tabular}




\begin{tabular}{cccc} 
Yes & $8(12.50)$ & $20(18.87)$ & \\
No & $56(87.50)$ & $86(81.13)$ & \\
PCOS Diagnosis & & & 0.078 \\
Yes & $10(15.63)$ & $29(27.36)$ & \\
No & $54(84.38)$ & $77(72.64)$ & 0.292 \\
Other Diagnosis & & & \\
Yes & $0(0.00)$ & $3(2.83)$ & \\
No & $64(100)$ & $103(97.17)$ & \\
Unknown & & & \\
Diagnosis & & & \\
Yes & $17(26.56)$ & $24(22.64)$ & \\
No & $47(73.44)$ & $82(77.36)$ & \\
Conception & & & \\
Yes & $29(45.31)$ & $47(44.34)$ & \\
No & $35(54.69)$ & $59(55.66)$ & \\
\hline
\end{tabular}

\section{Specific Aim 1 Results}

\section{1a: To estimate the effect of STI history on the probability of pregnancy.}

Among all sub-samples, variables included in initial modeling were those associated with either history of STI or pregnancy ( $P$-value $<=0.20)$. Age and obesity were also included, regardless of P-value, because of their established association with probability of conception. History of STI was the exposure of interest. Using a data-based method, confounders were identified and retained in the model, while non-confounders were removed.

Among the entire cohort $(\mathrm{N}=170)$, variables initially included were history of STI, age, obesity, blood pressure, race, alcohol use, smoking status, AMH levels, and infertility diagnoses of tubal, ovarian, PCOS, or male. The final model included the following variables: history of STI, age, obesity, race, ovarian infertility diagnosis (Table 7). In the resulting model, those with a history of STI had 1.56 times the odds of achieving pregnancy compared with those without a 
history of STI, adjusted for age, BMI, race, and ovarian diagnosis. However, this estimate is nonsignificant $(95 \% \mathrm{Cl}=0.77-3.13)$.

Among the sub-sample of women with no ART $(\mathrm{N}=82)$, initial variables included history of STI, age, obesity, blood pressure, alcohol use, race, smoking status, and infertility diagnoses of tubal, ovarian PCOS, or male. The final model only included the variables of history of STI age, obesity, blood pressure, alcohol use, and tubal and ovarian infertility diagnoses (Table 7). Adjusting for these variables, those women with a history of STI had 2.75 times the odds of conceiving than those without a history of STI, although not significantly $(95 \% \mathrm{Cl}$ : $0.86-8.77)$. Additionally, an effect mediation analysis was conducted on this specific sub-sample, as tubal infertility diagnosis was retained in the model and is known to be caused by certain STIs. However, when the variable was taken out, there was no significant change in the effect measure of STI.

Lastly, among the sub-sample of women with ART ( $N=88)$, initial variables were history of STI, age, obesity, alcohol use, smoking status, AMH levels, and infertility diagnoses of tubal, ovarian, PCOS, and uterine. Variables retained in the final model included the following: history of STI, age, obesity, and race (Table 7). In this resulting model, those women with a history of STI had 1.19 times the odds of achieving pregnancy than those women without a history of STI (95\% Cl: $0.46-3.11)$.

After confounding assessments, the effect of STI on the probability of pregnancy among each sub-sample are shown in Table 8. 
Table 7: Final Logistic Regression Models for the Effect of History of STI on the Probability of Pregnancy Among Each Sub-Sample

\begin{tabular}{|c|c|}
\hline $\begin{array}{l}\text { Entire Cohort } \\
(\mathrm{N}=170)\end{array}$ & $\begin{array}{l}\log \left(\text { odds of Pregnancy) }=\beta_{0}+\beta_{1}{ }^{*} \text { History of STI }+\beta_{2}{ }^{*} \text { Age }+\beta_{3}{ }^{*} \text { Obesity }+\beta_{4}{ }^{*} \text { Black }{ }^{*}+\beta_{5}{ }^{*} \text { Other Race }{ }^{*}+\beta_{6}{ }^{*} \text { Ovarian }\right. \\
\text { Diagnosis }\end{array}$ \\
\hline $\mathrm{T}(\mathrm{N}=82)$ & $\begin{array}{l}\text { Log (odds of Pregnancy) }=\beta_{0}+\beta_{1}{ }^{*} \text { History of STI }+\beta_{2}{ }^{*} \text { Age }+\beta_{3}{ }^{*} \text { Obesity }+\beta_{4}{ }^{*} \text { Blood Pressure } 2+\beta_{5}{ }^{*} \text { Blood Pressure } 3+ \\
\beta_{6}{ }^{*} \text { Alcohol Use }+\beta_{7}{ }^{*} \text { Tubal Diagnosis }+\beta_{8}{ }^{*} \text { Ovarian Diagnosis }\end{array}$ \\
\hline $\mathbf{R T}(\mathbf{N}=88)$ & $\log \left(\right.$ odds of Pregnancy) $=\beta_{0}+\beta_{1}{ }^{*}$ History of $S T I+\beta_{2}{ }^{*}$ Age $+\beta_{3}{ }^{*}$ Obesity $+\beta_{4}{ }^{*} B$ \\
\hline
\end{tabular}

ART $(\mathrm{N}=88)$

*White = reference group

Table 8: Odds Ratios for the Effect of History of STI on Pregnancy Among All Sub-Samples

\begin{tabular}{lcc}
\hline & OR $(\mathbf{9 5 \%} \mathrm{Cl})$ & P-value \\
\hline Entire Cohort $(\mathbf{N}=\mathbf{1 7 0})^{\mathrm{a}}$ & $1.56(0.77-3.13)$ & 0.211 \\
No ART $(\mathbf{N}=\mathbf{8 2})^{\mathrm{b}}$ & $2.75(0.86-8.77)$ & 0.088 \\
${\text { With ART }(\mathbf{N}=\mathbf{8 8})^{\mathrm{c}}}^{1.19(0.46-3.11)}$ & 0.713 \\
\hline
\end{tabular}

a Adjusted for age, obesity, race, ovarian infertility diagnosis.

${ }^{b}$ Adjusted for age, obesity, blood pressure, alcohol use, tubal infertility diagnosis, ovarian infertility diagnosis.

${ }^{c}$ Adjusted for age, obesity, race. 


\section{1b: To estimate the effect of STI history on the time to pregnancy.}

To determine the effect of history of STI on time to pregnancy, Cox models were produced for each sub-sample. Variables included in each model were those that were retained in the respective logistic regression models from Specific Aim 1a. A time-varying variable of ART per cycle was also included in sub-samples \#1 and \#3, those of which contained ART cycles.

Among sub-sample \#1, the entire cohort $(\mathrm{N}=170)$, none of the variables tested by correlation of residuals with time, or by examining $\ln (-\ln )$ curves, violated the Proportional Hazards assumption. When producing the Cox model, the interaction of ART cycles*time was significant, meaning that the time-varying covariate of ART violated the Proportional Hazards assumption; the final Cox model was stratified by the ART cycles variable. In the resulting model, women with a history of STI became pregnant 1.27 times faster than those without a history of STI. However, this estimate was not significant. Cox survival curves of history of STI adjusted for all variables in the model (younger than 32, not obese, white, no ovarian infertility diagnosis) are shown in Figure 3. 


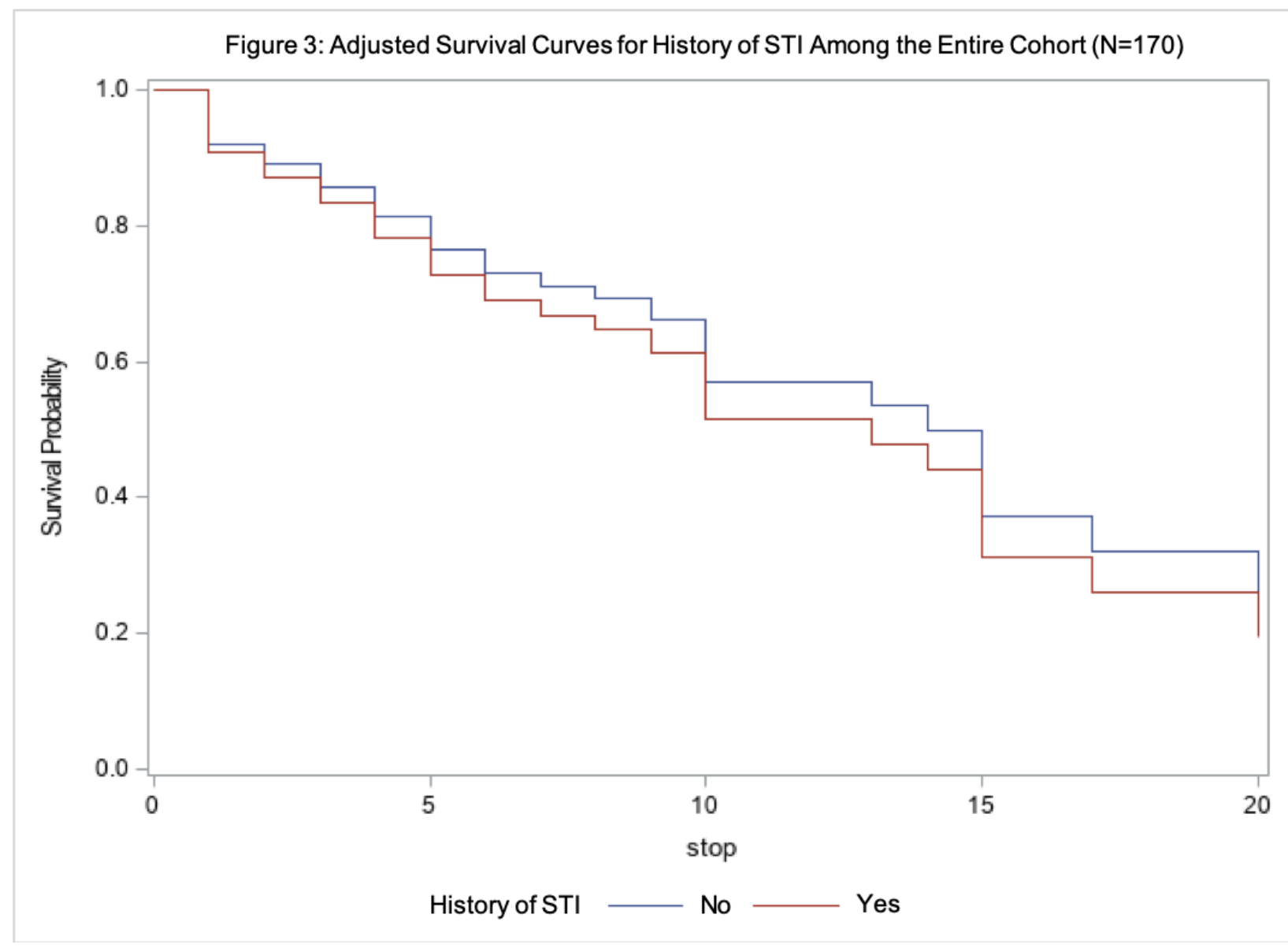

In sub-sample \#2, those women who never received ART $(\mathrm{N}=82)$, history of STI violated the Proportional Hazards assumption (Figure 4). No other variables violated the Proportional Hazards assumption. Because history of STI is the main exposure of interest, an extended Cox model was produced. The final Cox model was adjusted for all other variables included in the model and included Heaviside functions for history of STI before 6 months of follow-up time and at or after 6 months of follow-up time. Those women with a history of STI were becoming pregnant 5.51 times faster, significantly, than those without a history of STI before 6 months of follow up. From 6 months and later, those 
women with a history of STI were nonsignificantly becoming pregnant $30 \%$ slower than those without a history of STI.

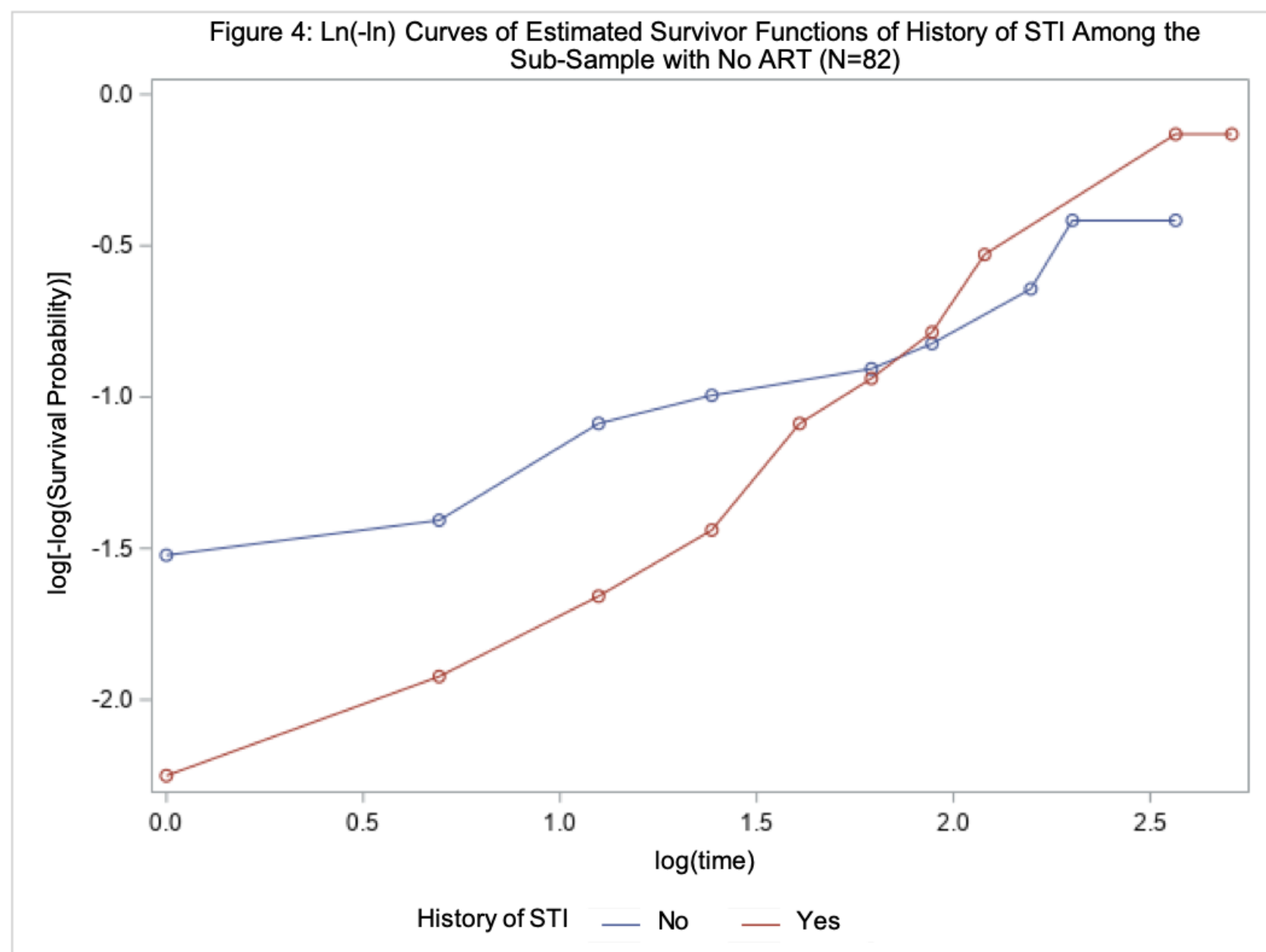

In the cohort of women who ever received ART during treatment, subsample \#3 $(\mathrm{N}=88)$, none of the constant variables violated the Proportional Hazards assumption. However, the $\ln (-\ln )$ curves of obesity (Figure 5) were questionable, so an extended Cox model was produced with Heaviside functions dichotomized at 6 months of follow-up time. Similar to sub-sample \#1, when ARTcycles*time was significant, and therefore the ART cycle variable violated the Proportional Hazards assumption. The final extended Cox model was 
stratified by the time-varying ART covariate, adjusted for all other variables, and included Heaviside functions for obesity and time. Women with a history of STI achieved pregnancy $28 \%$ faster than those without a history of STI, though this was not statistically significant $(\mathrm{HR}=1.28,95 \% \mathrm{Cl}=0.67-2.47)$. Cox survival curves for history of STI adjusted for all other variables (younger than 32, not obese, white) are shown in Figure 6.

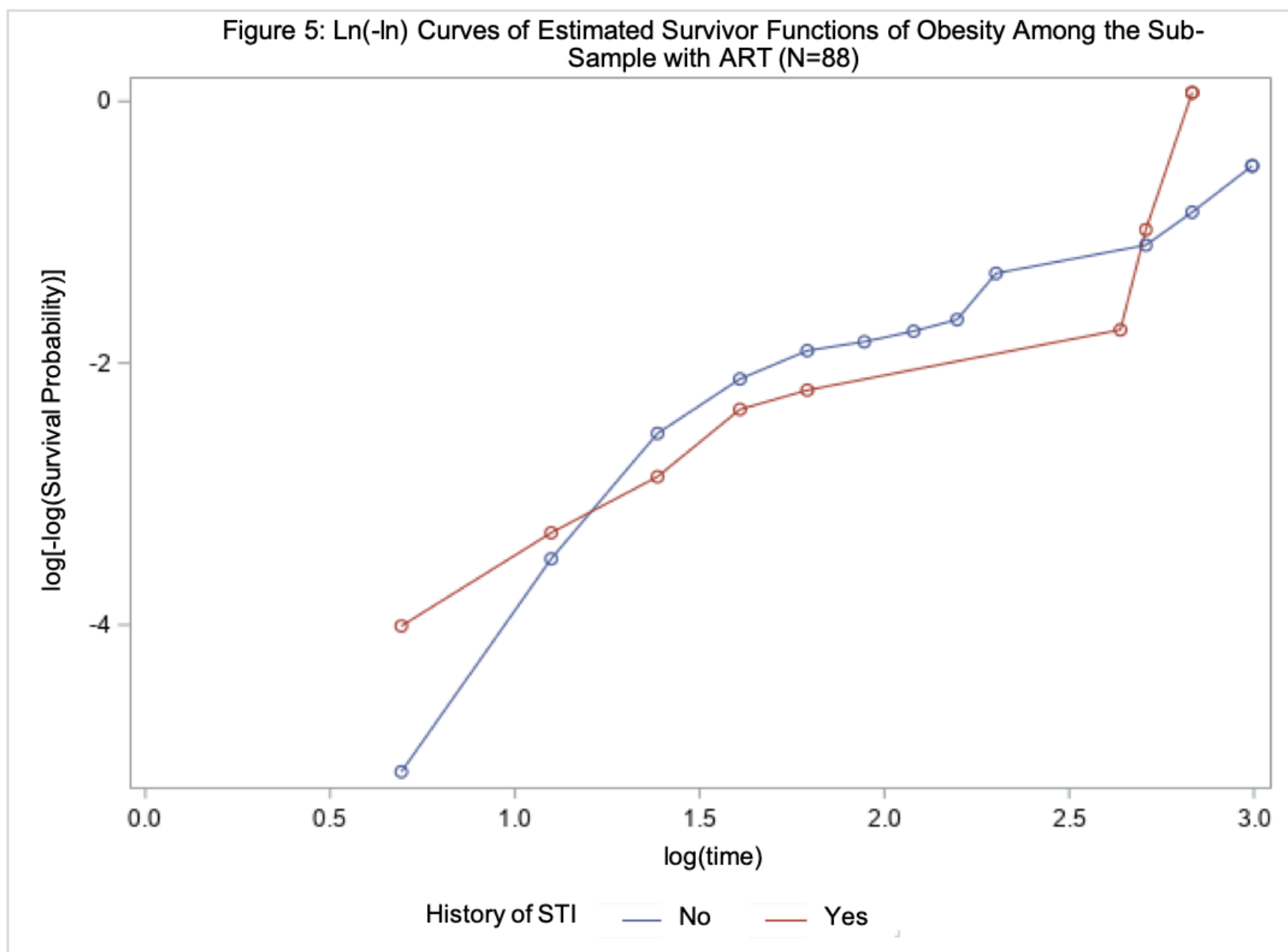




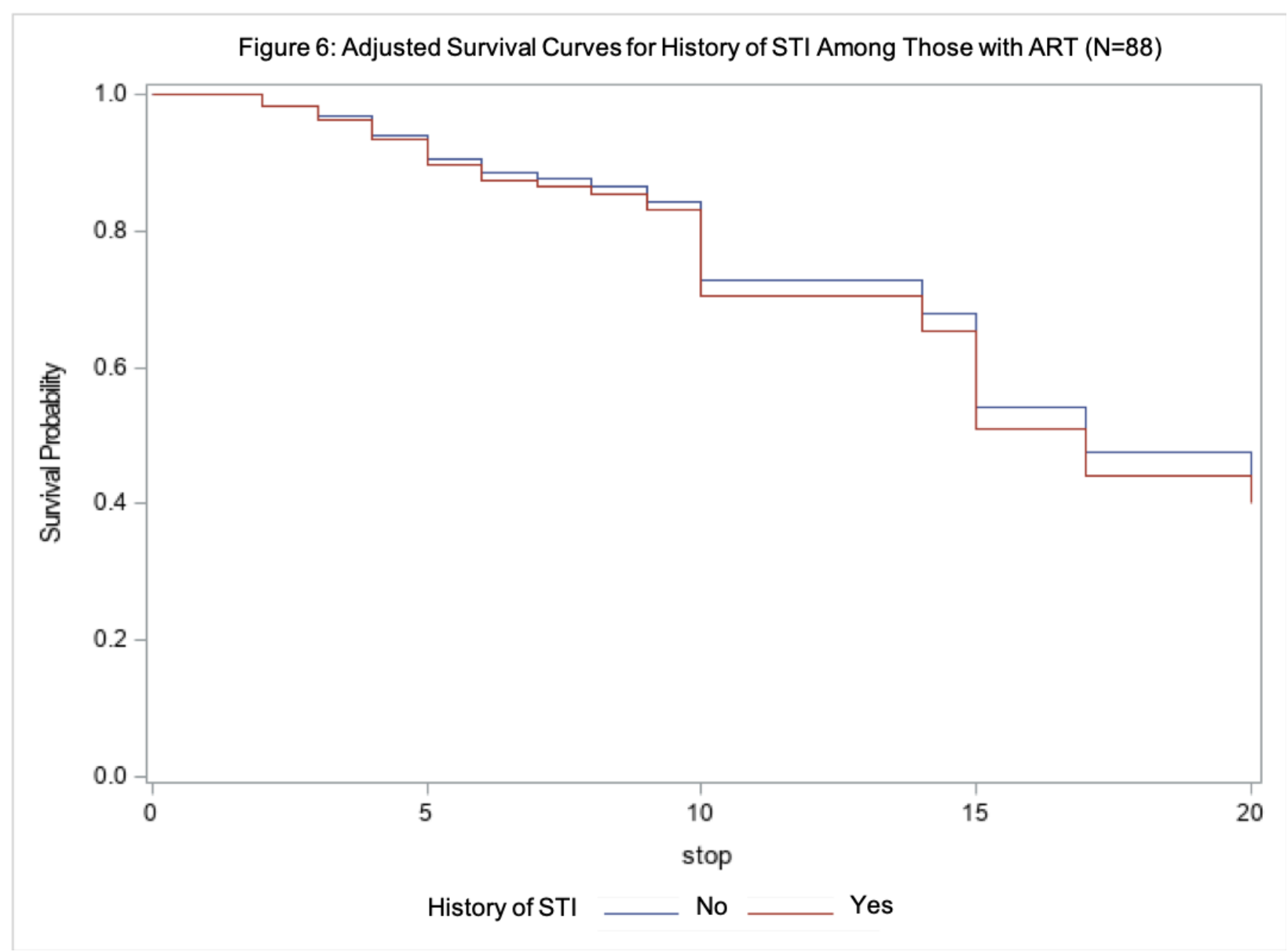

The effect of STI on the time of pregnancy among each sub-sample are shown in Table 9.

Table 9: Hazard Ratios for the Effect of History of STI on Time to Pregnancy Among All Sub-Samples

\begin{tabular}{ccc}
\hline & HR $(\mathbf{9 5 \%} \mathbf{C l})$ & P-value \\
\hline Entire Cohort $(\mathbf{N}=\mathbf{1 7 0})^{\mathbf{a}}$ & $1.27(0.78-2.06)$ & 0.339 \\
No ART (N=82) & & \\
$<6$ months & $5.51(2.09-12.00)$ & $<0.001$ \\
$\quad>=6$ months & $0.70(0.19-2.38)$ & 0.558 \\
With ART (N=88) & $1.28(0.67-2.47)$ & 0.449 \\
\hline
\end{tabular}

adjusted for age, obesity, race, ovarian infertility diagnosis, ART cycles

badjusted for age, obesity, blood pressure, alcohol use, tubal infertility diagnosis, ovarian infertility diagnosis

cadjusted for age, obesity, race, ART cycles 


\section{Specific Aim 2 Results}

\section{2a: To determine the factors that best predict the probability of pregnancy.}

Among all sub-samples, stepwise analysis was conducted with a P-value $<=0.20$ for entry into the model. Age and obesity were also included, regardless of $\mathrm{P}$-value, because of their established association with probability of conception. Resulting final models retained all other variables with P-values $<=$ 0.20 .

In sub-samples \#1 $(\mathrm{N}=170)$ and \#2 $(\mathrm{N}=82), \ln (\mathrm{AMH})$ was initially included in model testing. However, due to missing values of $\ln (\mathrm{AMH})$, the resulting models only contained 142 and 57 observations, respectively. In both models, $\ln (\mathrm{AMH})$ was not retained. For this reason, a second model was produced that excluded $\ln (\mathrm{AMH})$ from being tested in each sub-sample. The resulting final models therefore contained a larger sample.

Among the entire cohort $(\mathrm{N}=170)$, the resulting final model included the following variables: age, obesity, ovarian infertility diagnosis, PCOS, and history of HPV (Table 13). Obese women had significantly reduced odds ( $61 \%$ lower) of conceiving than women who were not obese. Older women also had $19 \%$ lower odds of becoming pregnant than younger women, but not significantly. Women with an ovarian infertility diagnosis, as well as women with a PCOS diagnosis, had roughly 2 times the odds of conceiving than women who did not have ovarian or PCOS diagnoses. However, these estimates were not statistically significant. Similarly, women with a history of HPV had nonsignificantly 2 times the odds of achieving a pregnancy. Estimates for the final predictive logistic 
regression model among sub-sample \#1 are shown in Table 10. In this subsample, a woman who is older than $32\left(X_{1}=1\right)$ and obese $\left(X_{2}=1\right)$, without an ovarian infertility diagnosis $\left(X_{3}=0\right)$, but who has PCOS $\left(X_{4}=1\right)$ and a history of $\operatorname{HPV}\left(X_{5}=1\right)$, would have 1.33 odds of pregnancy. A woman with these characteristics would have a moderate likelihood of conceiving, with a 0.57 probability.

Table 10: Predictive Logistic Regression Model on Conception for the Entire Cohort ( $\mathrm{N}=170)$

\begin{tabular}{|c|c|c|}
\hline & OR $(95 \% \mathrm{Cl})$ & P-value \\
\hline Age & & 0.549 \\
\hline$<32$ & 1.00 (Referent) & \\
\hline$>=32$ & $0.81(0.41-1.61)$ & \\
\hline Obese & & 0.007 \\
\hline No & 1.00 (Referent) & \\
\hline Yes & $0.38(0.19-0.77)$ & \\
\hline Ovarian Infertility & nosis & 0.094 \\
\hline No & 1.00 (Referent) & \\
\hline Yes & $2.12(0.88-5.10)$ & \\
\hline PCOS Diagnosis & & 0.078 \\
\hline No & 1.00 (Referent) & \\
\hline Yes & $2.22(0.91-5.34)$ & \\
\hline History of HPV & & 0.136 \\
\hline No & 1.00 (Referent) & \\
\hline Yes & $2.09(0.79-5.40)$ & \\
\hline
\end{tabular}

Among the women with no ART ( $\mathrm{N}=82)$, sub-sample \#2, the final model included age, obesity, and a PCOS diagnosis (Table 13). Women who were older, and women who were obese, had $33 \%$ and $65 \%$ reduced odds of conception, respectively, than younger women and women who were not obese. Conversely, women with PCOS had 3.4 times the odds of conception than those without PCOS. None of these estimates, however, were significant. Estimates for the final predictive logistic regression model among sub-sample \#2 are shown in 
Table 11. A woman who is younger than $32\left(X_{1}=0\right)$ but is obese $\left(X_{2}=1\right)$ and has PCOS $\left(X_{3}=1\right)$, would have 1.16 odds of pregnancy. Having these would result in a woman having moderate likelihood of conceiving, with a 0.53 probability.

Table 11: Predictive Logistic Regression Model on Conception for Women with No ART ( $\mathrm{N}=82)$

\begin{tabular}{lccc}
\hline & & OR (95\% Cl) & P-value \\
\hline Age & & 1.00 (Referent) & 0.439 \\
& $<32$ & $0.67(0.24-1.86)$ & \\
Obese & $>=32$ & 1.00 (Referent) & 0.059 \\
& No & 0.35 (0.12-1.04) & \\
& Yes & & 0.081 \\
PCoS Diagnosis & & \\
& No & 1.00 (Referent) & \\
& Yes & 3.38 (0.86 - 13.30) &
\end{tabular}

Among women who did receive ART ( $\mathrm{N}=88)$, sub-sample \#3, variables retained in the final model were age, obesity, $\ln (A M H)$, ovarian infertility diagnosis, and history of chlamydia (Table 13). Women with an ovarian infertility diagnosis had 8.3 times the odds of conception than those without an ovarian infertility diagnosis $(\mathrm{P}$-value $=0.01)$. Obese women had $55 \%$ lower odds of achieving pregnancy than women were not obese. For every one-unit increase in $\ln (\mathrm{AMH})$, the odds of pregnancy increased nonsignificantly by $41 \%$. Those women with a history of chlamydia had $69 \%$ lower odds of conceiving than those women who did not have a history of chlamydia $(P$-value=0.06). Estimates for the final predictive logistic regression model among sub-sample \#3 are shown in Table 12. A woman who is older than 32 years of age $\left(X_{1}=1\right)$, is not obese $\left(X_{2}=0\right)$, has $\mathrm{AMH}$ levels of $0.9 \mathrm{ng} / \mathrm{mL}\left(X_{3}=-0.11\right)$, has an ovarian infertility diagnosis $\left(X_{4}=1\right)$, and no history of chlamydia $\left(X_{5}=0\right)$, would have 8.9 odds of 
pregnancy. This combination of characteristics would result in a woman have a very high likelihood of pregnancy, with a 0.89 probability. 
Table 12: Predictive Logistic Regression Model on

Conception for Women with ART (N=88)

\begin{tabular}{|c|c|c|}
\hline & OR $(95 \% \mathrm{Cl})$ & P-value \\
\hline \multirow[t]{3}{*}{ Age } & & 0.933 \\
\hline & 1.00 (Referent) & \\
\hline & $1.05(0.35-3.13)$ & \\
\hline \multicolumn{2}{|l|}{ Obese } & 0.113 \\
\hline No & 1.00 (Referent) & \\
\hline Yes & $0.45(0.17-1.21)$ & \\
\hline $\ln (\mathrm{AMH})$ & $1.41(0.91-2.20)$ & 0.128 \\
\hline \multicolumn{2}{|c|}{ Ovarian Infertility Diagnosis } & 0.012 \\
\hline No & 1.00 (Referent) & \\
\hline Yes & $8.28(1.59-43.22)$ & \\
\hline \multicolumn{2}{|c|}{ History of Chlamydia } & 0.06 \\
\hline No & 1.00 (Referent) & \\
\hline Yes & $0.31(0.09-1.05)$ & \\
\hline
\end{tabular}

Table 13: Final Predictive Logistic Regression Models for Probability of Pregnancy Among Each Sub-Sample

\begin{tabular}{|c|c|}
\hline Entire Cohort $(\mathrm{N}=170)$ & $\begin{array}{l}\text { Log (odds of Pregnancy) }=\beta_{0}+\beta_{1}{ }^{*} \text { Age }+\beta_{2}{ }^{*} \text { Obesity }+\beta_{3}{ }^{*} \text { Ovarian Diagnosis }+\beta_{4}{ }^{*} \text { PCOS Diagnosis }+\beta_{5}{ }^{*} \text { History } \\
\text { of HPV }\end{array}$ \\
\hline No ART ( $=82)$ & Log (odds of Pregnancy) $=\beta_{0}+\beta_{1}{ }^{*}$ Age $+\beta_{2}{ }^{*}$ Obesity $+\beta_{3}{ }^{*}$ PCOS Diagnosis \\
\hline ART $(\mathrm{N}=88)$ & $\begin{array}{l}\text { Log (odds of Pregnancy) }=\beta_{0}+\beta_{1}{ }^{*} \text { Age }+\beta_{2}{ }^{*} \text { Obesity }+\beta_{3}{ }^{*} \ln (A M H)+\beta_{4}{ }^{*} \text { Ovarian Diagnosis }+\beta_{5}{ }^{*} \text { History of } \\
\text { Chlamydia }\end{array}$ \\
\hline
\end{tabular}




\section{2b: To determine the factors that best predict the time to pregnancy.}

Predictive Cox models were produced to determine the time to pregnancy for each sub-sample. Variables included in each model were those that were retained in the respective logistic regression models from Specific Aim 2a. In sub-samples \#1 and \#3, the ART per cycle, the time-varying covariate, was also included.

Upon testing the Proportional Hazards assumption in sub-sample \#1 $(\mathrm{N}=170)$ via correlation between Schoenfeld residuals of variables and time, history of HPV violated the Proportional Hazards assumption, with a correlation P-value of 0.01 . By examining the log-negative log curves, no other variables violated the Proportional Hazard assumption. Therefore, an extended Cox model was produced with history of $\mathrm{HPV}^{\star}$ time. Additionally, when producing the model with ARTcycle*time included, this interaction term was significant. Therefore, the time-varying ARTcycle variable violated the Proportional Hazards assumption, and the final model was additionally stratified by ARTcycles. The resulting final model is shown in Table 14. The only statistically significant finding was for history of HPV, which was associated with increased likelihood of conception, especially early during follow-up. Older women became pregnant $27 \%$ slower than younger women. Similarly, obese women achieved pregnancy $30 \%$ slower than non-obese women. Women with an ovarian infertility diagnosis conceived $29 \%$ faster than women who did not have an ovarian infertility diagnosis.

Similarly, women with PCOS became pregnant $11 \%$ faster than women without PCOS. Early into follow-up, women with a history of HPV were conceiving faster 
than women without a history of HPV. At 3 months of follow-up, those with a history of HPV were conceiving 2.5 times faster, significantly, than those without a history of HPV. At 6 months, women with a history of HPV were becoming pregnant $37 \%$ faster than those without HPV, but not significantly. At 9 months, hazards are reversed, and those with a history of HPV start to become pregnant slower than those without HPV, and even slower at 12 and 15 months. These estimates, however, are not significant. In general, the effect of having a history of HPV is inversely related to time; those with a history of HPV conceived faster than those without a history of HPV early on, and as time progressed, they conceived slower and slower than those without a history. 
Table 14: Predictive Cox Model of Conception for the Entire Cohort ( $\mathrm{N}=170)$ Stratified by ART per Cycle

\begin{tabular}{|c|c|c|}
\hline & $\mathrm{HR}(95 \% \mathrm{Cl})$ & P-value \\
\hline Age & & 0.177 \\
\hline$<32$ & 1.00 (Referent) & \\
\hline$>=32$ & $0.73(0.46-1.16)$ & \\
\hline Obese & & 0.136 \\
\hline No & 1.00 (Referent) & \\
\hline Yes & $0.70(0.44-1.12)$ & \\
\hline \multicolumn{2}{|c|}{ Ovarian Infertility Diagnosis } & 0.364 \\
\hline No & 1.00 (Referent) & \\
\hline Yes & $1.29(0.74-2.24)$ & \\
\hline PCOS & & 0.680 \\
\hline No & 1.00 (Referent) & \\
\hline Yes & $1.11(0.68-1.82)$ & \\
\hline History of HPV & & 0.038 \\
\hline No & 1.00 (Referent) & \\
\hline At 3 Months & $2.52(1.15-5.56)$ & 0.021 \\
\hline At 6 Months & $1.37(0.85-2.22)$ & 0.194 \\
\hline At 9 Months & $0.75(0.29-1.96)$ & 0.555 \\
\hline At 12 Months & $0.41(0.08-2.12)$ & 0.285 \\
\hline At 15 Months & $0.22(0.02-2.36)$ & 0.212 \\
\hline
\end{tabular}

Upon testing the Proportional Hazards assumption for variables included in sub-sample \#2 (N=82), no violations occurred. The final Cox model is shown in Table 15. Among the women who never received ART, older women conceived $23 \%$ slower than younger women. Similarly, obese women conceived 52\% slower than women who were not obese. Women with PCOS achieved pregnancy 2 times faster than women without PCOS. None of these estimates, however, were significant. 
Table 15: Predictive Cox Model of Conception

for Women with No ART ( $\mathrm{N}=82)$

\begin{tabular}{ccc}
\hline & HR (95\% Cl) & P-value \\
\hline Age & & 0.507 \\
$<32$ & 1.00 (Referent) & \\
$>=32$ & $0.77(0.36-1.66)$ & \\
Obese & & 0.091 \\
No & 1.00 (Referent) & \\
Yes & $0.48(0.21-1.12)$ & \\
PCOS & & 0.118 \\
No & 1.00 (Referent) & \\
Yes & $2.09(0.83-5.28)$ & \\
\hline
\end{tabular}

In sub-sample \#3 ( $\mathrm{N}=88)$, all initial variables included in modeling met the Proportional Hazards assumption. When ARTcycle*time was included in the model, the estimate was significant, and therefore violated the Proportional Hazards assumption. The final Cox model was therefore stratified by ART per cycle. The final Cox model for women who ever received ART is shown in Table 16. Among those women who ever received ART, age was not associated with conception rate. Obese women achieved pregnancy $28 \%$ slower than women who were not obese. For every one unit increase in $\ln (\mathrm{AMH})$, pregnancy occurred $9 \%$ faster; conception occurred faster with increased $\mathrm{AMH}$ levels. Those women with an ovarian infertility diagnosis were becoming pregnant $33 \%$ faster than women without an ovarian infertility diagnosis. Lastly, women with a history of chlamydia achieved pregnancy $16 \%$ slower than those without a history of chlamydia. None of these estimates, however, were significant. 
Table 16: Predictive Cox Model for Women with ART $(\mathrm{N}=88)$ Stratified by ART per Cycle

\begin{tabular}{lccc}
\hline & & HR $(95 \%$ Cl) & P-value \\
\hline Age & & 0.987 \\
& $<32$ & 1.00 (Referent) & \\
Obese & $>=32$ & $1.01(0.53-1.90)$ & \\
& No & 1.00 (Referent) & 0.334 \\
& Yes & $0.72(0.37-1.40)$ & \\
In(AMH) & $1.09(0.88-1.35)$ & 0.449 \\
Ovarian Infertility Diagnosis & 0.427 \\
& No & 1.00 (Referent) & \\
& Yes & 1.33 (0.66 - 2.68) & \\
History of Chlamydia & & 0.644 \\
& No & 1.00 (Referent) & \\
Yes & 0.84 (0.39 - 1.78)
\end{tabular}




\section{F. DISCUSSION}

This thesis identified predictors of successful conception and assessed the effects of history of STI on the likelihood of conception among a cohort of women seeking fertility counseling. Prior evidence suggests that certain STIs, such as chlamydia and gonorrhea, can cause tubal factor infertility by means of PID [11, 12, 85-88]. However, in no studies of conception among infertile couples is STI a factor of conception. This study, to the best of our knowledge, is the first to consider and explore the effect of history of STI on the likelihood of conception among infertile women.

The findings of this study show that, among infertile women, history of STI has a strong positive association with likelihood of pregnancy and less time to achieve pregnancy. This finding is not consistent with previous literature claiming that certain STIs can cause infertility [11, 12, 85-88]. However, in these mechanisms, the STI goes untreated, and thereby causes PID and, subsequently, tubal factor infertility. In the current population, none of the women tested positive for a current STI, but rather reported having an STI in the past. Hence, the assumption is made that the infertile women of this population who have ever had an STI were able to treat the STI before PID and tubal damage occurred. This is supported by the effect mediation analysis between tubal infertility and the effect of STI on pregnancy in sub-sample \#2; removing the variable did not affect the OR of history of STI on conception. Additionally, an 
assumption can be made that women with a history of STI are more likely to have higher frequencies of coital activity, thereby increasing their likelihood of conception and resulting in becoming pregnant faster. However, intercourse frequency was not collected from our participants, and therefore could not be included in modeling. Future studies assessing how history of STI affects the likelihood of pregnancy in infertile women should include a measure of coital frequency. It should also be noted that the current study started with a population that consisted of some women who were already infertile so the progression of an STI could not be followed to determine a true causal relationship between STI and its effects on conception.

Among sub-sample \#1 $(\mathrm{N}=170)$, the logistic regression and survival analysis are in agreement; the OR for history of STI are estimated in the same direction as the HR for history of STI. The same is only true in sub-sample \#2 $(\mathrm{N}=82)$ before 6 months, where both the odds and the hazards are greater in those with a history of STI; after 6 months, those with a history of STI have lower hazards. Likewise, among sub-sample \#3, the OR and HR for history of STI agree: history of STI increases the odds and the hazards of pregnancy.

This thesis also determined which factors predict pregnancy among a cohort of women seeking fertility counseling. Previous studies among infertile women have found that factors significantly associated with pregnancy were secondary infertility $[57,59]$, shorter duration of infertility $[9,55,57-59,61]$, younger female age $[3,4,6,8,9,56,57,59]$, younger male age [9], higher sperm volume and sperm motility [5,56], number of ART treatments [8], and 
infertility diagnoses [2, 3] including unexplained [3, 5, 7, 8, 57, 59], male factor $[57,59]$, endometriosis [3, 57], tubal factor [2, 57], and ovarian factor $[2,7,58]$. In this study, however, the only factors found to be significantly associated with pregnancy were obesity (among sub-sample \#1), which reduced probability of conception, and ovarian infertility diagnosis (among sub-sample \#3), which was associated with greater likelihood of conception. Additionally, the only factor found to be significantly associated with the time to conception among infertile women was history of HPV (among sub-sample \#1), which was associated with faster time to conception.

Among sub-sample \#1 $(\mathrm{N}=170)$, the logistic regression and survival analysis are in agreement among all predictors. However, the OR and HR for history of HPV only agree during the first 6 months, where those with a history of HPV have increased odds and hazards of pregnancy; after 6 months, the hazards are higher those without a history of HPV. In sub-sample \#2 (N=82), effect measures are in agreement; for each predictor, its respective OR and HR are estimated in the same direction. Likewise, in sub-sample \#3 $(\mathrm{N}=82)$, for all predictors, effect measures are in agreement.

Interestingly, among those women who did receive ART, sub-sample \#3 $(\mathrm{N}=88)$, women with an ovarian infertility diagnosis had 8 times the odds of conceiving and conceived $33 \%$ faster than women without an ovarian infertility diagnosis. The question remains as to why an ovarian infertility diagnosis increases the odds of and decreases the time it takes to becoming pregnant. The answer likely lies in the fact that most ovarian diagnoses can be overcome by 
either lifestyle changes, such as weight management, or ART, such as OI; or when OI fails, IVF [46].

Additionally, among the women who never received ART, sub-sample \#2 $(\mathrm{N}=82)$, those with PCOS had 3 times the odds of conceiving and conceived 2 times faster than those who did not have PCOS. Again, this is likely due to the fact that PCOS can achievably be overcome, and, for certain cases, requires no ART; obese women with PCOS can overcome their infertility with weight loss, while nonobese women can overcome their infertility with OI hormone pills [46].

It is also interesting that among sub-sample \#3 $(\mathrm{N}=88)$, those with a history of chlamydia had nonsignificantly lower odds of conceiving on than those without chlamydia; this may be due to chance or it may be that chlamydia has a different anatomical impact than other STIs, such as increasing the likelihood of PID.

In descriptive analyses among each sub-sample, lower blood pressure was nonsignificantly associated with achieving pregnancy. It is possible that high blood pressure is an indicator for poor underlying cardiovascular health.

Additionally, obesity, a known factor of infertility, is associated with hypertension [97].

\section{Spontaneous Conception Rates}

In this cohort of 170 women receiving fertility counseling, there were a total of $41(24.1 \%)$ spontaneous pregnancies. 
Among the women who never received ART $(\mathrm{N}=82)$, there were 32 (39.0\%) spontaneous pregnancies within a cumulative follow-up time of 484 months, for a rate of 6.61 pregnancies every 100 months. The 3 -year risk for spontaneous pregnancy would be calculated to be $90.7 \%$. However, this is assuming that fecundability of the population remains constant through time, when in reality, fecundability decreases over time as the more fertile women are removed from the sample. Other studies among untreated infertile women report 3-year spontaneous conception rates at $24.9 \%$ [59], 38.2\% [57], and 72.0\% [58]. The much larger probability of pregnancy reported here could be explained by the fact that our sample likely has higher fecundability than other studies of women seeking fertility treatment. For example, we did not require women to meet any definition of infertility in order to be included in the study. In fact, of the 82 women who remained untreated by ART, 35 (42.6\%) had an unknown infertility diagnosis, which was not considered in other studies.

Among the women who did receive ART (N=88), 9 (10.2\%) women achieved a spontaneous pregnancy within a cumulative follow-up time of 483 months, for a rate of 1.8 spontaneous pregnancies every 100 months. With this rate, a 5-year risk for spontaneous conception would be $66.0 \%$, again making the strong assumption of constant fecundability over time for all women who did receive ART. One study reported a 5-year live-birth after spontaneous conception rate of $18.1 \%$ [60]. Another study, however, reported a 5-year spontaneous conception rate of $60.2 \%$ [9]. However, that study only included women with an unexplained infertility diagnosis, whereas the current sub-sample 
consisted of 25 (28.4\%) women with an unexplained infertility diagnosis.

Unexplained infertility is an infertility diagnosis related to the strongest likelihood of pregnancy. These results are comparable to the current study's report of $66.0 \%$, as the population used in the current study is probably more fertile than most other populations.

\section{Strengths and Limitations}

The LOUSSI Study is longitudinal and prospective in design. One strength of the design is the ability to lower and potentially eliminate the amount of recall bias from participants. Follow-up with participants occurred starting at 6 months post-enrollment and will continue every 6 months. With short follow-up intervals, there is a small likelihood of women forgetting their conception date or how long they continued trying to conceive. Additionally, the study design allows the collection of time and any wanted time varying covariates, making survival analyses and Cox models possible to produce; therefore, measures of effect are more accurate than without time data.

Another strength of the study is the retention rate. Of the original 264 participants, follow-up data was collected for 170 (64.4\%). However, of the participants that consented to being recontacted ( $n=157)$, follow-up data was successfully collected 128 (81.5\%) of them, with 42 (40.0\%) additional follow-up data via medical records for those who did not consent to being recontacted $(n=105)$. 
There are several limitations to the current study, with the most obvious being the sample size. The small sample of 170 has the potential to create low power and imprecise measures of effect, which is evident, as several of the reported ORs and HRs have wide confidence intervals. Additionally, given the small sample size, the reported estimates of effect measures by have been totally left up to chance.

Selection and misclassification bias were likely present in this study. In the recruitment phase of the study, physicians of the REI clinic were 'gatekeepers' of the study and determined which of their patients they recommended participating in the LOUSSI Study. This filter led to only a portion of eligible women being invited to enroll into the study. Additionally, selection bias likely occurred in the recontact phase, as women who had achieved a pregnancy were probably more likely to be successfully recontacted. This bias would lead to elevated conception rates being reported. In addition, the main predictor for specific aim 1 was history of STI, which was a self-reported variable and likely suffered from some misclassification. It is likely that some women who ever had a history of STI did not report it, either intentionally or otherwise. Additionally, unless collected via medical records, pregnancy data was also a self-reported variable. The potential misclassification of these variables would result in inaccurate estimates of effect measures.

Another limitation that should be noted is that the time data was collected by months, and not by menstrual cycles. Some women have irregular 
menstruation, and cycle length varies from woman to woman; therefore using follow-up time in months does not accurately reflect the number of cycles at risk.

In terms of fertility diagnoses, the cohort of women used for this study was not comparable to other populations assessed in conception studies. Multiple women in the LOUSSI Study were diagnosed with more than one infertility diagnosis, with some having up to three diagnoses. In other studies, women typically have one diagnosis; making it possible to determine effect estimates of each diagnosis, relative to one other reference diagnosis. However, in this study, effect estimates for diagnoses could only be determined by comparing those with a specific diagnosis to those without the same diagnosis.

Additionally, most other studies assess very specific populations, whether they be truly infertile, diagnosed with a certain infertility diagnosis, or by their treatment methods. The women in the LOUSSI Study were relatively heterogenous compared to other studies, in that some women had no infertility diagnosis and in the women's treatment methods could vary over time - whether by type of treatment or by status of treatment. With this heterogeneity interpreting effect estimates should be done cautiously; such varying data makes it difficult to produce accurate effect estimates.

\section{Suggestions for Further Research}

In future efforts assessing how history of STI affects the likelihood or time to conception, coital frequency should be collected, as the frequency of 
intercourse could be a key confounder in the relationship between history of STI and achieving a pregnancy.

Additionally, future studies should make great efforts to collect time data by menstruation cycles, and not in months, as some women do not have regular periods. This can be accomplished by collecting daily urine samples and measuring levels of reproductive hormones such as LH. Access to medical records is also an imperative part of a fertility study; access to detailed records of ART treatments, clearly defined diagnoses, and conception dates eliminate the potential for misclassification and recall bias. Daily diaries can ideally be used to record intercourse, menstruation and time-varying variables such as alcohol and smoking. 


\section{G. SUMMARY AND CONCLUSION}

This thesis aimed to identify predictors of pregnancy and the effect of STI history on probability of conception in a population of women seeking fertility counseling. This population was not a homogeneously infertile population, and $24 \%$ conceived naturally during follow-up. Obesity, the type of infertility diagnosis, and history of HPV were significant predictors of pregnancy in this small study. History of STI was associated with higher odds of pregnancy and shorter time to pregnancy, nonsignificantly however, regardless of ART treatment. This may be due to confounding by coital frequency; future studies of STI history and conception should make efforts to record intercourse frequency in a prospective manner. 


\section{REFERENCES}

1. Zegers-Hochschild, F., et al., International Committee for Monitoring Assisted Reproductive Technology (ICMART) and the World Health Organization (WHO) revised glossary of ART terminology, 2009. Fertil Steril, 2009. 92(5): p. 1520-4.

2. Cahill, D.J., et al., Likelihood of natural conception following treatment by IVF. J Assist Reprod Genet, 2005. 22(11-12): p. 401-5.

3. Hennelly, B., et al., Spontaneous conception after a successful attempt at in vitro fertilization/intracytoplasmic sperm injection. Fertil Steril, 2000. 73(4): p. 774-8.

4. Ludwig, A.K., et al., Spontaneous pregnancy after successful ICSI treatment: evaluation of risk factors in 899 families in Germany. Reprod Biomed Online, 2008. 17(3): p. 403-9.

5. Lande, Y., et al., Spontaneous conceptions following successful ART are not associated with premature referral. Hum Reprod, 2012. 27(8): p. 23803.

6. Shimizu, Y., et al., Spontaneous conception after the birth of infants conceived through in vitro fertilization treatment. Fertil Steril, 1999. 71(1): p. 35-9. 
7. Marcus, A.P., et al., Spontaneous pregnancies following discontinuation of IVF/ICSI treatment: an internet-based survey. Hum Fertil (Camb), 2016. 19(2): p. 134-41.

8. Troude, P., et al., Spontaneous pregnancies among couples previously treated by in vitro fertilization. Fertil Steril, 2012. 98(1): p. 63-8.

9. Brandes, M., et al., Unexplained infertility: overall ongoing pregnancy rate and mode of conception. Hum Reprod, 2011. 26(2): p. 360-8.

10. Paavonen, J. and W. Eggert-Kruse, Chlamydia trachomatis: impact on human reproduction. Hum Reprod Update, 1999. 5(5): p. 433-47.

11. Yeow, T.C., et al., Prevalence of plasmid-bearing and plasmid-free Chlamydia trachomatis infection among women who visited obstetrics and gynecology clinics in Malaysia. BMC Microbiol, 2016. 16: p. 45.

12. Cates, W., Jr., S.O. Rolfs Rt Jr Fau - Aral, and S.O. Aral, Sexually transmitted diseases, pelvic inflammatory disease, and infertility: an epidemiologic update. 1990(0193-936X (Print)).

13. Westrom, L., Influence of sexually transmitted diseases on sterility and ectopic pregnancy. Acta Eur Fertil, 1985. 16(1): p. 21-4.

14. Brunham, R.C., et al., Etiology and outcome of acute pelvic inflammatory disease. J Infect Dis, 1988. 158(3): p. 510-7.

15. Moller, B.R., et al., Serological evidence that chlamydiae and mycoplasmas are involved in infertility of women. J Reprod Fertil, 1985. 73(1): p. 237-40. 
16. Robertson, J.N., et al., Chlamydial and gonococcal antibodies in sera of infertile women with tubal obstruction. J Clin Pathol, 1987. 40(4): p. 37783.

17. Pereira, N., et al., Human Papillomavirus Infection, Infertility, and Assisted Reproductive Outcomes. J Pathog, 2015. 2015: p. 578423.

18. Souho, T., M. Benlemlih, and B. Bennani, Human papillomavirus infection and fertility alteration: a systematic review. PLoS One, 2015. 10(5): $p$. e0126936.

19. Eggert-Kruse, W., et al., Herpes simplex virus infection of the uterine cervix--relationship with a cervical factor? Fertil Steril, 2000. 73(2): p. 24857.

20. Cherpes, T.L., et al., The associations between pelvic inflammatory disease, Trichomonas vaginalis infection, and positive herpes simplex virus type 2 serology. Sex Transm Dis, 2006. 33(12): p. 747-52.

21. Zegers-Hochschild, F., et al., The International Glossary on Infertility and Fertility Care, 2017. Fertil Steril, 2017. 108(3): p. 393-406.

22. Division of Reproductive Health \& National Center for Chronic Disease Prevention and Health Promotion. Reproductive Health. 2019 [cited 2019; Available from:

\section{https://www.cdc.gov/reproductivehealth/infertility/index.htm.}

23. Gurunath, S., et al., Defining infertility--a systematic review of prevalence studies. Hum Reprod Update, 2011. 17(5): p. 575-88. 
24. Mascarenhas, M.N., et al., National, regional, and global trends in infertility prevalence since 1990: a systematic analysis of 277 health surveys. PLoS Med, 2012. 9(12): p. e1001356.

25. Chandra A, C.C., Stephen EH., Infertility and impaired fecundity in the United States, 1982-2010: Data from the National Survey of Family Growth. National health statistics reports; no 67. Hyattsville, MD: National Center for Health Statistics, 2013.

26. Khalaf, Y., ABC of subfertility. Tubal subfertility. Bmj, 2003. 327(7415): $\mathrm{p}$. 610-3.

27. Practice Committee of American Society for Reproductive Medicine, The role of tubal reconstructive surgery in the era of assisted reproductive technologies. Fertil Steril, 2008. 90(5 Suppl): p. S250-3.

28. Abrao, M.S., L. Muzii, and R. Marana, Anatomical causes of female infertility and their management. Int J Gynaecol Obstet, 2013. 123 Suppl 2: p. S18-24.

29. Westrom, L., et al., Pelvic inflammatory disease and fertility. A cohort study of 1,844 women with laparoscopically verified disease and 657 control women with normal laparoscopic results. 1999(0148-5717 (Print)).

30. diZerega, G.S., Biochemical events in peritoneal tissue repair. Eur J Surg Suppl, 1997(577): p. 10-6.

31. Grimbizis, G.F., et al., Clinical implications of uterine malformations and hysteroscopic treatment results. Hum Reprod Update, 2001. 7(2): p. 16174. 
32. Valle, R.F. and G.E. Ekpo, Hysteroscopic metroplasty for the septate uterus: review and meta-analysis. J Minim Invasive Gynecol, 2013. 20(1): p. $22-42$.

33. Practice Committee of the American Society for Reproductive Medicine, Uterine septum: a guideline. Fertil Steril, 2016. 106(3): p. 530-40.

34. Wallach, E.E. and N.F. Vlahos, Uterine myomas: an overview of development, clinical features, and management. Obstet Gynecol, 2004. 104(2): p. 393-406.

35. The Practice Committee of the American Society for Reproductive Medicine in collaboration with The Society of Reproductive Surgeons, Myomas and reproductive function. Fertil Steril, 2008. 90(5 Suppl): $p$. S125-30.

36. Westendorp, I.C., et al., Prevalence of Asherman's syndrome after secondary removal of placental remnants or a repeat curettage for incomplete abortion. Hum Reprod, 1998. 13(12): p. 3347-50.

37. Thomson, A.J., et al., The management of intrauterine synechiae. Curr Opin Obstet Gynecol, 2009. 21(4): p. 335-41.

38. Giudice, L.C. and L.C. Kao, Endometriosis. Lancet, 2004. 364(9447): p. 1789-99.

39. Halis, G. and A. Arici, Endometriosis and inflammation in infertility. Ann N Y Acad Sci, 2004. 1034: p. 300-15. 
40. Sampson, J.A., Peritoneal endometriosis due to the menstrual dissemination of endometrial tissue into the peritoneal cavity. Am J Obstet Gynecol, 1927. 14: p. 422-469.

41. Ludmir, J. and H.M. Sehdev, Anatomy and physiology of the uterine cervix. Clin Obstet Gynecol, 2000. 43(3): p. 433-9.

42. Lemert, M. and L. Mastroianni, Jr., Cervical factors in infertility. Clin Obstet Gynecol, 1974. 17(4): p. 29-43.

43. The Practice Committee of the American Society for Reproductive Medicine, Optimal evaluation of the infertile female. Fertil Steril, 2006. 86(5 Suppl 1): p. S264-7.

44. Lindsay, T.J., Vitrikas, K. R., Evaluation and Treatment of Infertility. Am Fam Physician., 2015. Mar 1(91(5)): p. 308-314.

45. Practice Committee of the American Society for Reproductive Medicine, Diagnostic evaluation of the infertile female: a committee opinion. Fertil Steril, 2015. 103(6): p. e44-50.

46. National Collaborating Centre for Women's and Children's Health, Fertility: Assessment and Treatment for People with Fertility Problems, in National Institute for Health and Care Excellence: Clinical Guidelines. 2013, Royal College of Obstetricians \& Gynaecologists and National Collaborating Centre for Women's and Children's Health.: London.

47. Hamilton-Fairley, D. and A. Taylor, Anovulation. Bmj, 2003. 327(7414): p. 546-9. 
48. Richard-Eaglin, A., Male and Female Hypogonadism. Nurs Clin North Am, 2018. 53(3): p. 395-405.

49. Jarow, J., et al., The Optimal Evaluation of the Infertile Male: AUA Best Practice Statement. 2011, American Urological Association.

50. Leaver, R.B., Male infertility: an overview of causes and treatment options. Br J Nurs, 2016. 25(18): p. S35-s40.

51. Jungwirth, A., et al., European Association of Urology guidelines on Male Infertility: the 2012 update. Eur Urol, 2012. 62(2): p. 324-32.

52. Juul, A., et al., Possible fetal determinants of male infertility. Nat Rev Endocrinol, 2014. 10(9): p. 553-62.

53. Ray, A., et al., Unexplained infertility: an update and review of practice. Reprod Biomed Online, 2012. 24(6): p. 591-602.

54. Glatstein, I.Z., B.L. Harlow, and M.D. Hornstein, Practice patterns among reproductive endocrinologists: the infertility evaluation. Fertil Steril, 1997. 67(3): p. 443-51.

55. Vardon, D., et al., [Spontaneous pregnancies in couples after failed or successful in vitro fertilization]. J Gynecol Obstet Biol Reprod (Paris), 1995. 24(8): p. 811-5.

56. Kupka, M.S., et al., Stress relief after infertility treatment--spontaneous conception, adoption and psychological counselling. Eur J Obstet Gynecol Reprod Biol, 2003. 110(2): p. 190-5.

57. Collins, J.A., E.A. Burrows, and A.R. Wilan, The prognosis for live birth among untreated infertile couples. Fertil Steril, 1995. 64(1): p. 22-8. 
58. Snick, H.K., et al., The spontaneous pregnancy prognosis in untreated subfertile couples: the Walcheren primary care study. Hum Reprod, 1997. 12(7): p. 1582-8.

59. Eijkemans, M.J., et al., Pregnancy chances on an IVF/ICSI waiting list: a national prospective cohort study. Hum Reprod, 2008. 23(7): p. 1627-32.

60. Pinborg, A., et al., Prospective longitudinal cohort study on cumulative 5year delivery and adoption rates among 1338 couples initiating infertility treatment. Hum Reprod, 2009. 24(4): p. 991-9.

61. Osmanagaoglu, K., et al., Spontaneous pregnancies in couples who discontinued intracytoplasmic sperm injection treatment: a 5-year followup study. Fertil Steril, 2002. 78(3): p. 550-6.

62. The Centers for Disease Control and Prevention. Defining Aduly Obesity. 2017 [cited 2019; Available from:

https://www.cdc.gov/obesity/adult/defining.html.

63. The World Health Organization. Body Mass Index - BMI. 2019 [cited 2019; Available from: http://www.euro.who.int/en/health-topics/diseaseprevention/nutrition/a-healthy-lifestyle/body-mass-index-bmi.

64. Best, D. and S. Bhattacharya, Obesity and fertility. Horm Mol Biol Clin Investig, 2015. 24(1): p. 5-10.

65. Hartz, A.J., et al., The association of obesity with infertility and related menstural abnormalities in women. Int J Obes, 1979. 3(1): p. 57-73. 
66. Roos, N., et al., Risk of adverse pregnancy outcomes in women with polycystic ovary syndrome: population based cohort study. Bmj, 2011. 343: p. d6309.

67. Shah, D.K., et al., Effect of obesity on oocyte and embryo quality in women undergoing in vitro fertilization. Obstet Gynecol, 2011. 118(1): $p$. 63-70.

68. Bellver, J., et al., Obesity and poor reproductive outcome: the potential role of the endometrium. Fertil Steril, 2007. 88(2): p. 446-51.

69. Dickey, R.P., et al., Relationship of clomiphene dose and patient weight to successful treatment. Hum Reprod, 1997. 12(3): p. 449-53.

70. Ferlitsch, K., et al., Body mass index, follicle-stimulating hormone and their predictive value in in vitro fertilization. J Assist Reprod Genet, 2004. 21(12): p. 431-6.

71. Maheshwari, A., L. Stofberg, and S. Bhattacharya, Effect of overweight and obesity on assisted reproductive technology--a systematic review. Hum Reprod Update, 2007. 13(5): p. 433-44.

72. Practice Committee of the American Society for Reproductive Medicine, Smoking and infertility: a committee opinion. Fertil Steril, 2018. 110(4): p. 611-618.

73. Augood, C., K. Duckitt, and A.A. Templeton, Smoking and female infertility: a systematic review and meta-analysis. Hum Reprod, 1998. 13(6): p. 1532-9. 
74. Hart, R.J., Physiological Aspects of Female Fertility: Role of the Environment, Modern Lifestyle, and Genetics. Physiol Rev, 2016. 96(3): p. 873-909.

75. Sharma, R., et al., Lifestyle factors and reproductive health: taking control of your fertility. Reprod Biol Endocrinol, 2013. 11: p. 66.

76. Sharara, F.I., et al., Cigarette smoking accelerates the development of diminished ovarian reserve as evidenced by the clomiphene citrate challenge test. Fertil Steril, 1994. 62(2): p. 257-62.

77. Bouyer, J., et al., Risk factors for ectopic pregnancy: a comprehensive analysis based on a large case-control, population-based study in France. Am J Epidemiol, 2003. 157(3): p. 185-94.

78. Soares, S.R., et al., Cigarette smoking affects uterine receptiveness. Hum Reprod, 2007. 22(2): p. 543-7.

79. Klonoff-Cohen, $\mathrm{H}$., et al., Effects of female and male smoking on success rates of IVF and gamete intra-Fallopian transfer. Hum Reprod, 2001. 16(7): p. 1382-90.

80. Tal, R. and D.B. Seifer, Ovarian reserve testing: a user's guide. Am J Obstet Gynecol, 2017. 217(2): p. 129-140.

81. Norbert Gleicher. FSH Levels by Age - Follicle Stimulating Hormone Levels with Chart. 2019 2-6-19 [cited 2019 3-11-19]; Available from: https://www.centerforhumanreprod.com/dor/fsh-levels/. 
82. Steiner, A.Z., et al., Association Between Biomarkers of Ovarian Reserve and Infertility Among Older Women of Reproductive Age. Jama, 2017. 318(14): p. 1367-1376.

83. Goswami, M. and D. Nikolaou, Is AMH Level, Independent of Age, a Predictor of Live Birth in IVF? J Hum Reprod Sci, 2017. 10(1): p. 24-30.

84. Dondik, Y., et al., The Value of Anti-Mullerian Hormone in Predicting Clinical Pregnancy After Intrauterine Insemination. J Obstet Gynaecol Can, 2017. 39(10): p. 880-885.

85. Tsevat, D.G., et al., Sexually transmitted diseases and infertility. Am J Obstet Gynecol, 2017. 216(1): p. 1-9.

86. Westrom, L., Incidence, prevalence, and trends of acute pelvic inflammatory disease and its consequences in industrialized countries. Am J Obstet Gynecol, 1980. 138(7 Pt 2): p. 880-92.

87. Westrom, L.V., Sexually transmitted diseases and infertility. Sex Transm Dis, 1994. 21(2 Suppl): p. S32-7.

88. Cates, W., Jr. and J.N. Wasserheit, Genital chlamydial infections: epidemiology and reproductive sequelae. 1991(0002-9378 (Print)).

89. Choi, J.H., et al., Effects of Caffeine Consumption by Women and Men on the Outcome of In Vitro Fertilization. J Caffeine Res, 2011. 1(1): p. 29-34.

90. Al-Saleh, I., et al., The effect of caffeine consumption on the success rate of pregnancy as well various performance parameters of in-vitro fertilization treatment. Med Sci Monit, 2010. 16(12): p. Cr598-605. 
91. Abadia, L., et al., The association between pre-treatment maternal alcohol and caffeine intake and outcomes of assisted reproduction in a prospectively followed cohort. Hum Reprod, 2017. 32(9): p. 1846-1854.

92. Bolumar, F., et al., Caffeine intake and delayed conception: a European multicenter study on infertility and subfecundity. European Study Group on Infertility Subfecundity. Am J Epidemiol, 1997. 145(4): p. 324-34.

93. Hakim, R.B., R.H. Gray, and H. Zacur, Alcohol and caffeine consumption and decreased fertility. Fertil Steril, 1998. 70(4): p. 632-7.

94. Lopez-del Burgo, C., et al., Alcohol and Difficulty Conceiving in the SUN Cohort: A Nested Case-Control Study. Nutrients, 2015. 7(8): p. 6167-78.

95. Grodstein, F., M.B. Goldman, and D.W. Cramer, Infertility in women and moderate alcohol use. Am J Public Health, 1994. 84(9): p. 1429-32.

96. American College of Obstetricians and Gynecologists Committee on Gynecologic Practice and Practice Committee, Female age-related fertility decline. Committee Opinion No. 589. Fertil Steril, 2014. 101(3): p. 633-4.

97. Barekat, M. and S. Ahmadi, Hypertensive Disorders in Pregnant Women Receiving Fertility Treatments. Int J Fertil Steril, 2018. 12(2): p. 92-98. 


\section{CURRICULUM VITA}

Lindsey Adelle Wood

Department of Epidemiology and Population Health | 485 East Gray Street, Louisville, KY 40202 | lawood06@louisville.edu

\section{EDUCATION}

University of Louisville, Louisville, Kentucky

MS Epidemiology 2019

Thesis: "Probability of conception after fertility counseling and the association of sexually transmitted infections with pregnancy in the LOUSSI Study"

Chair: Kira C. Taylor, Ph.D., Associate Professor of Epidemiology

Southern Arkansas University, Magnolia, Arkansas

\section{BS Pre-Health Biology 2017}

Minor: Chemistry

Cum Laude

\section{RELATED EXPERIENCE}

Graduate Research Assistant, Superfund Trainee April 2018 - Present University of Louisville Superfund Research Center, Envirome Institute University of Louisville Department of Communication, Epidemiology, School of Medicine

Drs. Joy Hart and Kandi Walker

Superfund Research Translation Core Description: A promotion of increasing the awareness of affected communities on exposure risk and its health effects as well as translation of study findings to affected communities and stakeholders. Assisted with communication study findings to stakeholder groups and developed and employed multiple methods of communicating information. Superfund Project 1 - VOCs and Cardiometabolic Injury Description: An environmental health study aimed to evaluate the effects of VOCs on various adverse human health outcomes at the Superfund site in Louisville, KY. Assisted with health study data collection, including survey design and administration, consenting participants, and data entry. Supported participant recruitment via community events and door-to-door initiatives.

\section{Graduate Research Assistant April 2018 - Present}

University of Louisville, Envirome Institute Green Heart Louisville 
University of Louisville Department of Communication, Epidemiology, School of Medicine

Drs. Joy Hart and Kandi Walker

Green Heart Louisville Description: An environmental community health study examining the relationships between community greenness, air quality and other environmental factors, and many facets of human health. Participated in all phases of community engagement, collaborated with project partners and research team leads, facilitated relationships with community members and organizations, built ongoing relationships for multiyear project, led community meetings and presentations, and recruited and retained study participants through several novel methods.

\section{Graduate Research Volunteer August 2018 - Present}

University of Louisville, Department of Epidemiology and Population Health Dr. Kira Taylor

Louisville Tobacco Smoke Exposure, Genetic Susceptibility, and Infertility Study Description: A clinical-based study assessing the relationship between NAT2 acetylator type, smoking status, and fertility outcomes. Assisted in primary data collection of 6 month follow up, created data sets, and analyzed data as relevant to thesis project.

\section{PAPERS AND PRESENTATIONS}

Joy L. Hart, Lindsay K. Tompkins, Jack Pfeiffer, Lindsey A. Wood, Austin Zachary, Shelby Carter, Delana Gilkey, Delvon Mattingly, Angel Thornsbury, Kandi L. Walker. Growing Together: Community Engagement and Student Involvement. Southern States Communication Association Annual Meeting, Montgomery, Alabama, April 2019.

Lindsay K. Tompkins, Clara G. Sears, Alexander S. Lee, Courteney Smith, Allison Siu, Jack Pfeiffer, Lindsey A. Wood, Austin Zachary, Kandi L. Walker, Joy L. Hart. Engaging Communities, Engaging Change: Rural Middle and High School Youth and Tobacco Products. Southern States Communication Association Annual Meeting, Montgomery, Alabama, April 2019.

Lindsay K. Tompkins, Jack Pfeiffer, Lindsey A. Wood, Austin Zachary, Kandi L. Walker, Joy L. Hart. Translating Research for Community Members: Learning Partnerships and Change Mechanisms. Southern States Communication Association Annual Meeting, Montgomery, Alabama, April 2019.

Joy L. Hart, Lauren Heberle, Kandi L. Walker, Lindsay K. Tompkins, Jamar Wheeler, Jack Pfeiffer, Lindsey A. Wood, Delana Gilkey, Austin Zachary, and Aruni Bhatnagar. UofL Superfund Research Center: Communicating and engaging across disciplinary, professional, and institutional boundaries. Superfund Research Program Annual Meeting, Sacramento, California, November 2018 
Lindsey A. Wood, Joy L. Hart, Kandi L. Walker, Lindsay K. Tompkins, Jack Pfeiffer, Austin Zachary, Delana Gilkey, Delvon Mattingly, Shelby Carter, Angel Thornsbury. Environmental Health: Engaging a Community in Research, Partnership, and Practice. Kentucky Communication Association Conference, Prestonburg, Kentucky, September 2018

\section{PROFESSIONAL WORKSHOPS}

U.S. Department of Homeland Security, FEMA: IS-00800.c National Response Framework, An Introduction; October 8, 2018

Texas A\&M Engineering Extension Service in cooperation with the Department of Homeland Security FEMA: AWR-160-W WMD/Terrorism Awareness for Emergency Responders; October 15, 2018

U.S. Department of Homeland Security, FEMA: IS-00200.b ICS for Single Resources and Initial Action Incident, ICS-200; October 8, 2018

QPR Institute: QPR Suicide Prevention Gatekeeper Certificate; September 9-15, 2018

U.S. Department of Homeland Security, FEMA: IS-00100.c Introduction to Incident Command System, ICS-100; August 10,2018

U.S. Department of Homeland Security, FEMA: IS-00700.a National Incident Management System (NIMS) And Introduction; October 31, 2017 